دور الممارس العام فى الخدمة الاجتماعية لتنمية الوعى للعاملين للوقاية من جائحة كورونا

\author{
إعداد

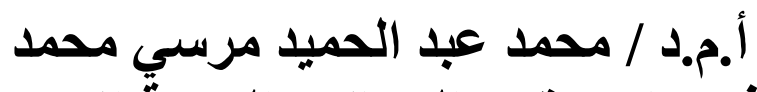 \\ أستاذ مساعد بقسم المجالات الخدمةً الاجتماعية \\ بالمعهز العالى للخدمة الاجتماعية
}


تهدف الدراسة الى التعرف على دور الممارس العام فى الخدمة الاجتماعية مع العاملين فى مجال التجميل والنظافة بالمجالس المحلية لتتمية وعيهم بجائحة كوروناوتحديد معوقاته وتحديد مقترحات لمواجهتها، وتتتمى هذه الدراسة وفقاً لأهدافها إلى نمط الدراسات الوصفية التحليلية ، فقد استخدم الباحث

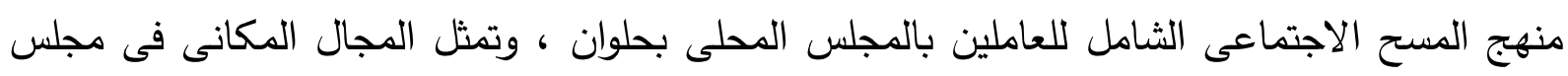

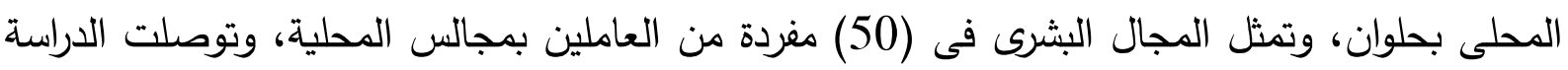

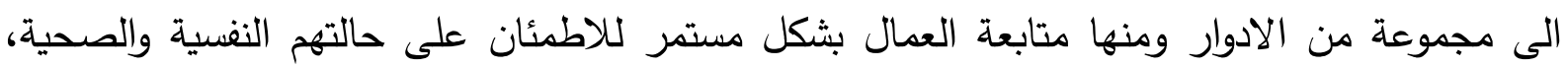

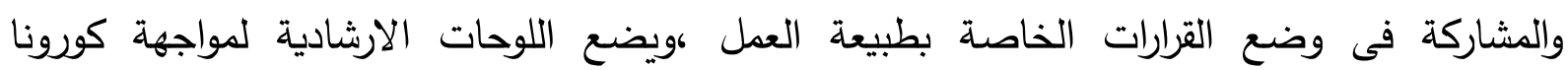

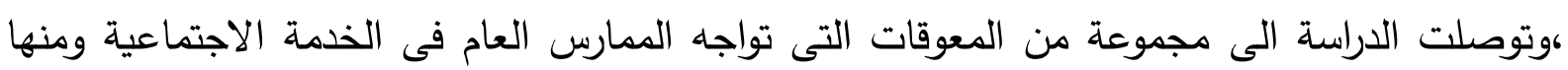

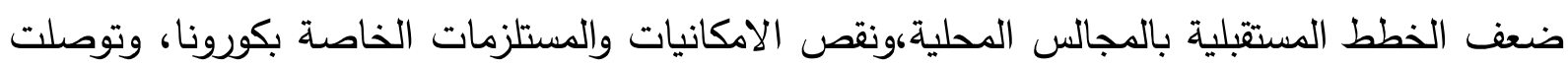

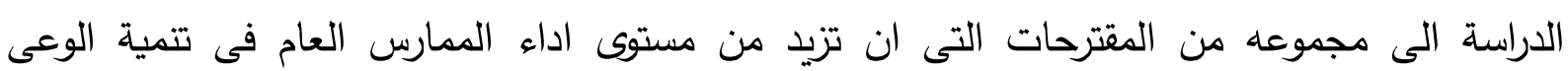

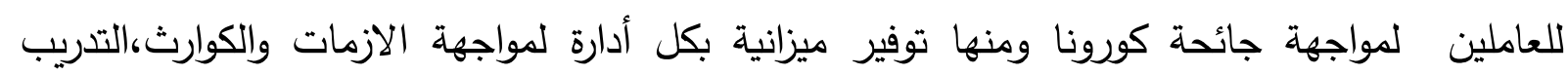
المستمر للعاملين للتعامل مع جائحة كورونا وغيرها. الكلمات المفتاحية: تنمية الوعى ، الممارسة العامة 


\section{Summary study}

The study aims to identify the role of the general practitioner in social service with workers in the field of beauty and hygiene in the local councils to develop their awareness of the Corona pandemic and identify its obstacles and identify proposals to face them, and this study belongs in accordance with its objectives to the pattern of descriptive studies, the researcher used The approach of the comprehensive social survey of workers of the local council of Helwan, representing the field of housing in the local council of Helwan, and represents the human field in (50) individual workers in local councils, and the study reached a set of roles, including the follow-up of workers continuously to check on The study found a set of obstacles facing the general practitioner in the social service, including the weakness of future plans in local councils, the lack of resources and requirements for Corona, and the study found a set of proposals that increase the performance of the general practitioner in the development of awareness of workers to face the Corona pandemic, including providing a budget in all departments to cope with crises and disasters, and the continuous training of workers to deal with the Corona pandemic and others.

Keywords: the development of awareness, general practice 
تعد التتمية البشرية هي الركيزة الأساسية التي من خلالها يحدث الإصلاح والازدهار في أي مجتمع من

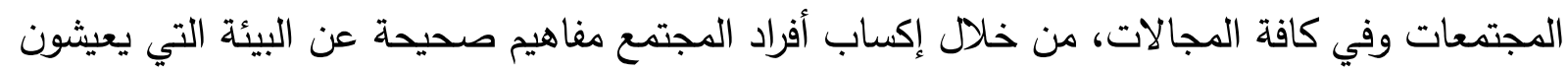

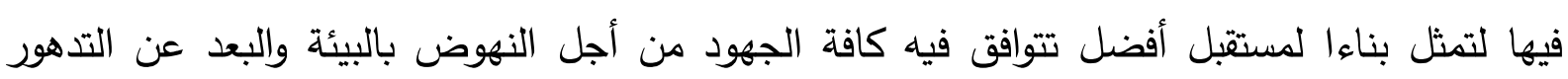

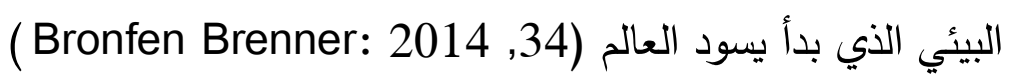

وكثر الحديث في الآونة الأخيرة حول البيئة، والمشكلات البيئية، ودعا مناصرو حقوق البيئة الدعوة

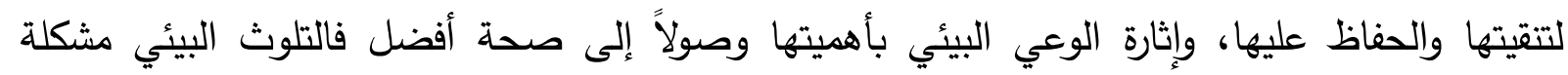

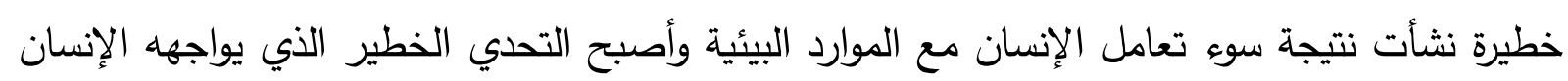

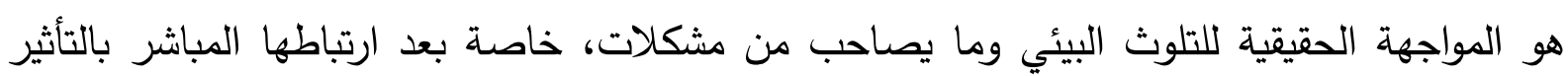

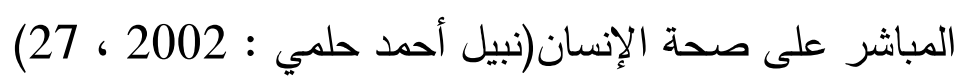

وتعتبر جائحة كورونا أحد أهم المشاكل البيئية الملحة التي بدأت تأخذ أبعاداً بيئية اقتصادية واجتماعية

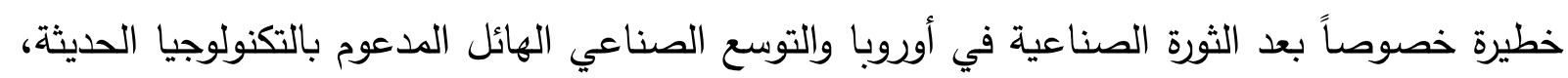

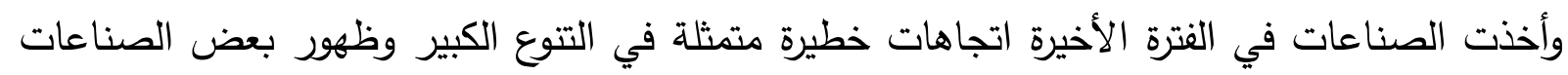

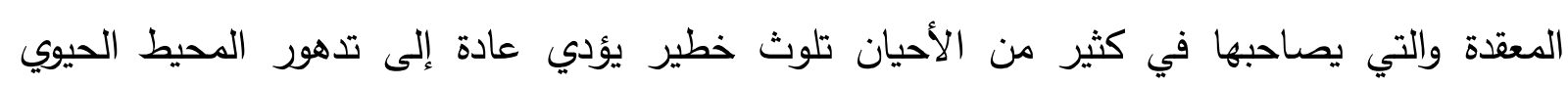
والقضاء على تتظيم البيئة العالمية (Mary Ellen:2013,78) وهذا ما أكدت عليه إحدى الدراسات على ضرورة نشر المعرفة البيئية لدى أفراد المجتمع للحد من التلوث

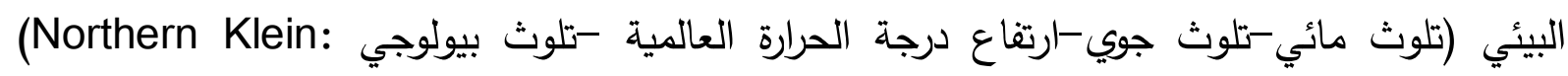

ودراسة آخري أشارت إلى أن إدراك الفرد للبيئة المحيطة به يساعده على تكوين اتجاه إيجابي نحو البيئة

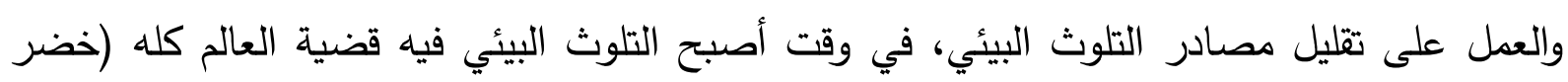
) مخيمر :1990)

وتختلف الملوثات التي تؤدي إلى الإخلال بالطبيعة وتوازنها مما تحدث تغير كمي وكيفي في عناصر

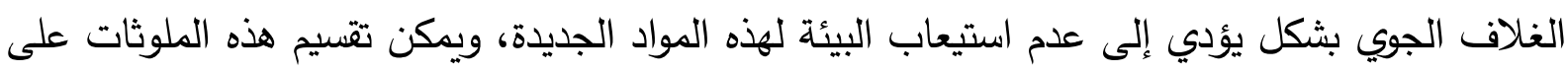
النحو التالي: na

الملوثات بحسب طبيعتها (محد أمين ومصطفى محمود: 2009، 98) 
أ -الملوثات ذات الطبيعة الفيزيائية -:وهي ظواهر فيزيائية مادية وتشمل الإشعاع (وهو أثد خطراً على

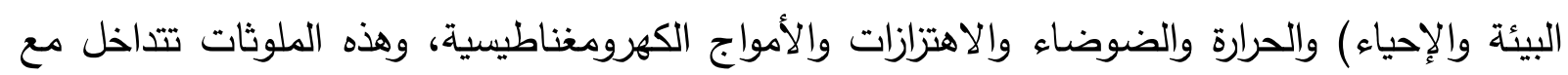
الخصائص الفيزيائية لعناصر البيئة أو المادة الحية. والاهراء

ب -الملوثات الطبيعة الكيماوية -:وهي مجموعة واسعة من الملوثات الأكثر انتشارا في البيئة، وتثمل

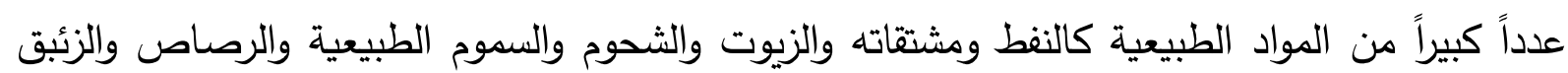

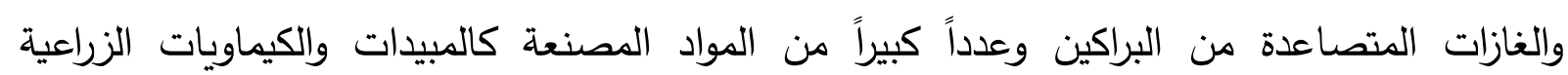

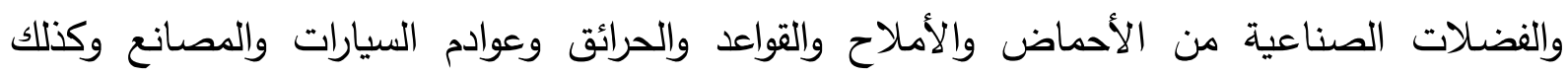
الجسيمات الدقيقة الناتجة من مصانع الإسمنت والكيماويات السائلة عندما تلقى في التربة أو الماء.

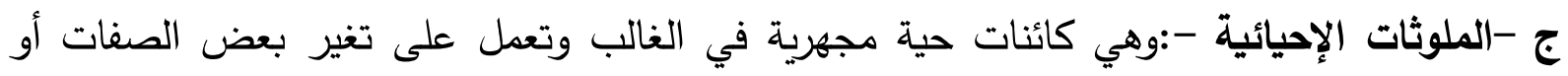

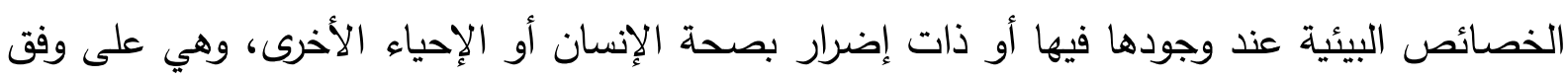

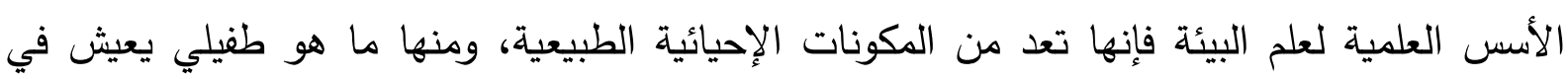

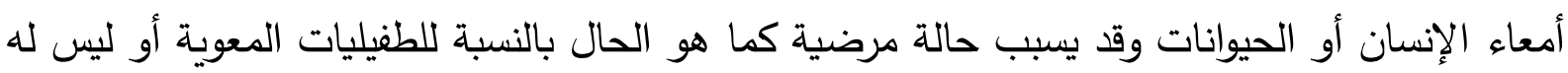
تأثير صحي ضار كما في حالة العديد من البكتريا المعوية. وإن حماية البيئة بكل عناصرها (ماء - هواء - تربة)، من التلوث ليست مسئولية الحكومة وحدها بل إنها مسئولية ذات أطراف ثلاثة يشترك فيها المتمع من خلال هيئاته ومؤسساته والحكومة بأجهزتها ويبقى أهم

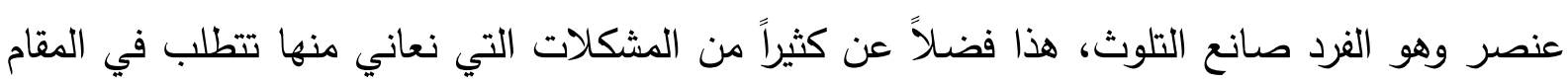
الأول التحضر والتحكم في التلوث. كما ترجع معظم المشكلات والقضايا البيئية نتيجة للتصرفات الخاطئة

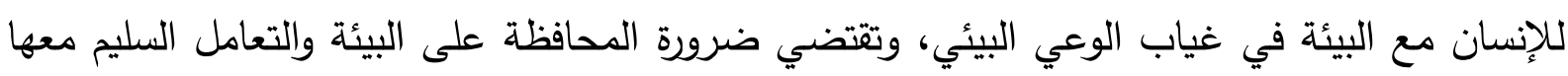

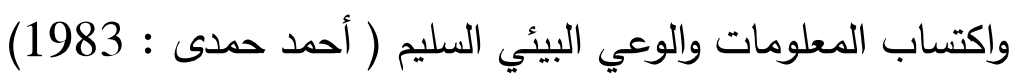
وهذا ما أكدت عليه إحدى الدراسات بضرورة تتمية السلوك البيئي الإيجابي لدى أعضاء الجماعة حتى

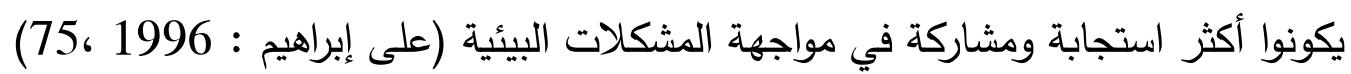
ويعتبر فيروس كورونا من الفيروسات التى تتنج عن الملوثات الاحيائية التى تتنقل عن طريق الرذاذ او

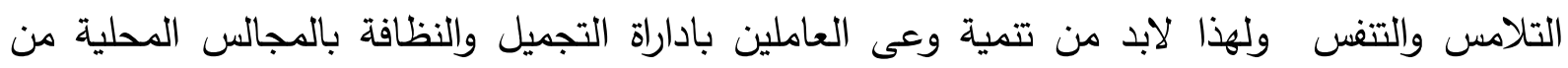

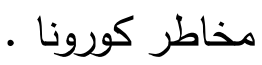

وتتزايد أعداد الاصابات بفيروس كورونا في مصر بشكل مستمر وهذا ما يشير اليه الجدول الاتى : جدول (أ) إحصائيات إنتشار فيروس كورونا في مصر فير 


\begin{tabular}{|r|r|r|}
\hline وفاة & ses & \\
\hline 6.813 & 103.913 & 119.281 \\
\hline
\end{tabular}

حيث يوضح الجدول السابق ان اعداد الاصابات تبلغ 119.281 مصاب بفيروس كورونا وكذلك عدد المتعافين من فيروس كورونا يبلع عددهم 103.913 متعافى وعدد الوفيات قد بلغ عدهم 6.813 متوفى ، حيث ان الاعداد فى تزايد مستمر علماً بان هذه الاحصائية صادره بتاريخ $12 / 9$ /2020. (إحصائيات إنتشار فيروس كورونا في مصر،2https://www.sis.gov.eg/Story/ $(1: 00$

وبما انه لا يوجد حتى الآن أي لقاح للوقاية من فيروس كورونا/ كوفيد 19، لذلك فإن أفضل طريقة للوقاية من المرض هي تجنب التعرض لهذا الفيروس أصلاً، ويعتقد أن الفيروس ينتشر بشكل رئيس من هون شخص لآخر ، وخصوصاً بين الأشخاص الذين هم على اتصال وثيق مع بعضهم ( مسافة 6 أقدام/ 2 متر تقريباً),من خلال رذاذ الجهاز التنفسي الناتج من سعال أو عطاس الثخص المصاب وتحدد طرق الوقاية فى الاتى(https://www.ilajak.com/blog/corona-symptoms-causes علاجات طبية - فيروس كورونا اعراضه واسبابه ووالوقايه منه،

$$
\text { البقاء في المنزل }
$$

في حالة العزل المنزلي، فيجب عليك:

(أ) عدم مغادرة المنزل لأي سبب كان، مع ممارسة الرياضة لمرة واحدة على الأقل في اليوم الواحد.

(ب) حافظ على مسافة مترين من الأثخاص الآخرين.

(ج)اطلب حاجياتك عن طريق الهاتف أو عبر الإنترنت.

(د) إلغاء أو تأجيل استقبال وزيارة الأصدقاء والعائلة في المنزل.

$$
\text { التباعد الإجتماعي }
$$


التباعد الجسدي أو التباعد الاجتماعي بتجنب التجمعات العامة الكبيرة أو وسائل النقل العام، والبقاء بعيدًا عن الآخرين عندما تكون في مكان عام، مع الحفاظ على مسافة مترين (6 أقدام) على الأقل بينك وبين أي شخص يسعل أو يعطس.

لأن السعال أو العطاس ينتج قطرات (رذاذ) سائلة صغيرة، وقد تحتوي هذه القطرات على الفيروس، وهو ما يؤدي للإصصابة.

\section{3- (النظافة الشخصية}

الحرص على النظافة الثخصية عموماً، ونظافة اليدين خصوصاً، عبر غسلهما بالماء والصابون لمدة لا تقلٌ عن 20 ثانية، وخصوصاً بعد العودة في أي مكان عام أو بعد السعال أو العطاس. وإذا لم يكن الصابون والماء متوفرين بسهولة، فاستخدم معقاً لليدين يحتوي ما لا يقل عن نسبة 60٪ من الكحول، عبر وضع المعقم على سطح يديك وفركهما معًا حتى يجف.

ويجدر التذكير بضرورة تجنب لمس الأنف والفم والعينين بأيدٍ غير مغسولة، لأن ذلك أدعى للإصابة.

$$
\text { 4- دور الكمامات في الوقاية من كورونا }
$$

يجب على الثخص المصاب ارتداء الكمامات عند الاقتراب من الأشخاص الآخرين، وقبل دخول أماكن

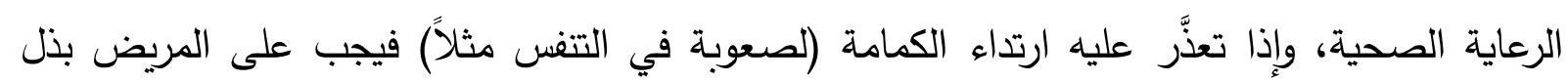
قصارى جهده لتغطية السعال والعطاس، كما يجب على الأشخاص الذين يعيشون مع الشخص المصاب ارتداء الكمامة عند الاقتراب منه.

$$
\text { 5- استخدام مطهرات للوقاية من كورونا }
$$

يجب مسح الأسطح التي يلمسها الأشخاص عادةً بالصابون المنزلي العادي أو أي مُنظِّف آخر، ثم شطفها بالماء. كما ينصـح بعد ذلك باستخدام مُطهِّر منزلي، مثل المُبِِّض (الكلور)

وتعد الخدمة الاجتماعية أحد المهن المتخصصة التي تشارك في تحمل المسئولية لتحقيق التتمية المجتمية، لذلك يجب على الأخصائي الاجتماعي تجويد دوره المهني وأداءه الوظيفي الذي أصبح محكوم بتقنيات المهنة. حيث تمثل أزمة الخدمة الاجتماعية في مؤسسات الممارسة بشكل أساسي في 
تشتيت جهود المهنة والمهنيين وعدم تركيزها في مجالاتها الأساسية مما أضعف فعالية المهنة في التصدي لمشكلات المجتمع الحقيقية (جمال شحاتة حبيب: 44،2009)

وتعد الممارسة العامة من اهم واحدث النماذج التى فرضت نفسها على ممارسة الخدمة الاجتماعية خلال الربع الاخير من القرن العشرين ، حيث أنها تمثل اتجاها يبتعد عن النمط التقليدى للخدمة الاجتماعية (سليمان واخرون : 2005، 26 الاحنر منرن

واعتمد منظور الممارسة العامة في الخدمة الاجتماعية في المجال التمية المحلية على أهمية تتمية شخصية العاملين وزيادة وعيهم الصحى والبيئي على أسس معرفية ومهارية تبني على المعرفة الحرة، وأدوات للتخخل المهني وإستراتيجيات تعتمد على المشكلات والاحتياجات المتعددة للعميل والموارد والأهداف والظروف البيئية، ولذلك هدفت الممارسة العامة في مجال التتمية المحلية على مساعدة العاملين على حل المشكلات والحصول على الموارد المتاحة وتسهيل التقاعلات بين الأنساق المختلفة في البيئة الاجتماعية والاستفادة من مؤسسات المجتمع (أبو الحسن عبد الموجود إبراهيم: 2010، 229). ويعد تطوير الأخصائي الاجتماعي لأدائه في المجالس المحلية يرتبط بمدى التزامه بمبادئ المهنة التي يدعمها الميثاق الأخلاقي للخدمة الاجتماعية، ومتطلبات وواجبات العمل المنوط تنفيذها تبعاً للجهاز الوظيفي التابع له في وزارة التتمية المحلية ، وعليه فإن الاخصائى الاجتماعى الذي يمارس أدواره المهنية تتمية الوعى للعاملين للوقايه من جائحة كورونا.

وهن هنا ظهرت حاجة الأخصائي الاجتماعي المستمرة إلى اكساب المزيد من المعارف والمهارات والخبرات بما يصقل شخصيته المهنية بحيث تكون أكثر قدرة على أداء مهامه ومسئولياته والإسهام بدور أكثر فاعلية في تحقيق التمية في المجتمع من خلال تحسين ممارسته المهنية وتجويد الخدمة المهنية التي يقدمها لوحدة العمل سواء كانت أفراد أو جماعات أو أسر أو منظمات أو مجتمعات . محمدئ الجوهري، عبد الحميد عبد المحسن: 1991، 23)

ثانيا الاراسات السابقة أ- دراسات عن الوعى الصحي والبيئى 1- دراسة خطابية ورواشدة (2000م) هدفت الى معرفة مستوي الوعي الصحي لدي طالبات كليات المجتمع الحكومية والتي أظهرت نتائجها أن مستوى الوعي الصحي لدى طالبات كليات المجتمع الحكومية في الأردن كان متدنياً. 
2- دراسة علي بن حسن الأحمدي (2004م ، 1424هـ) هدفت الى معرفة مستوي الوعي الصحي

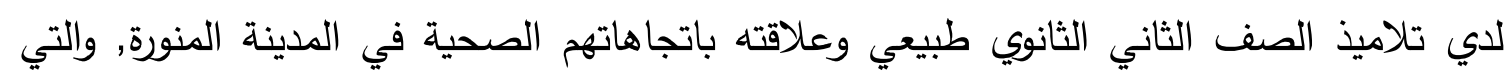

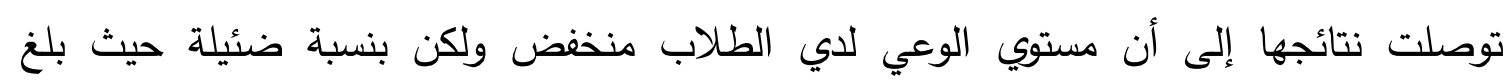

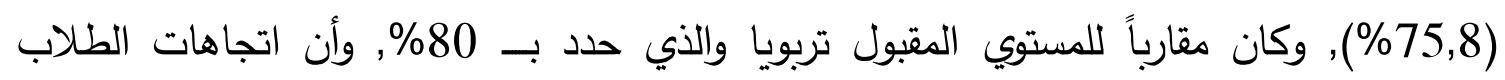

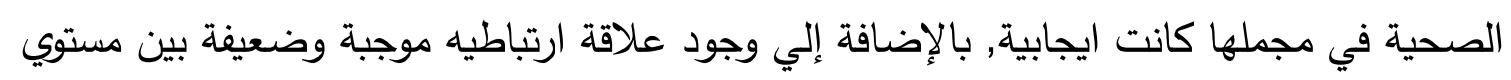
الوعي الصحي للتلاميذ واتجاهاتهم الصحية. 3- دراسة أحمد باريان (2004م ، 1425هـ) بعنوان دور وسائل الإعلام في التثقيف الصحي للمرأة

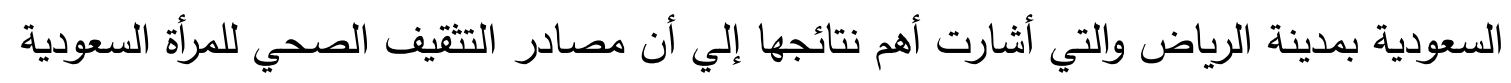

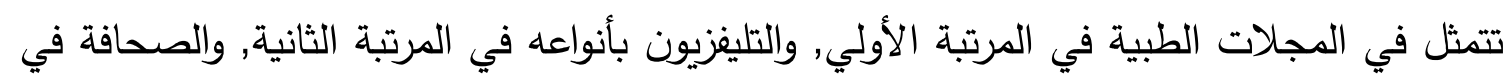

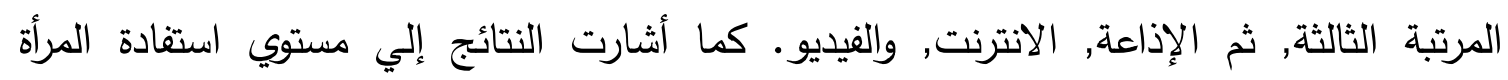

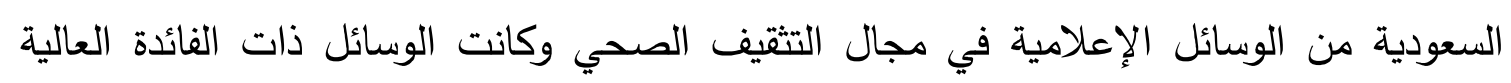

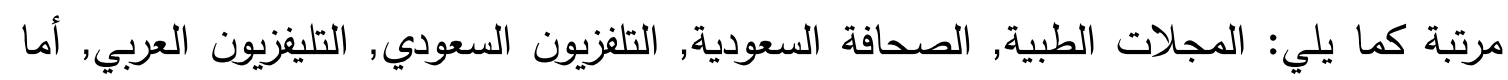

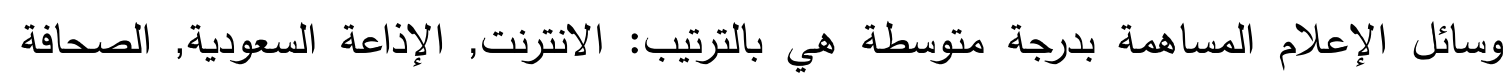

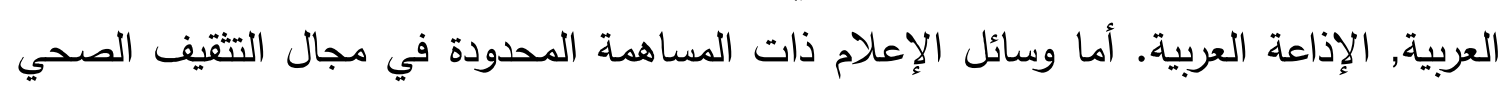
هي الفيديو.

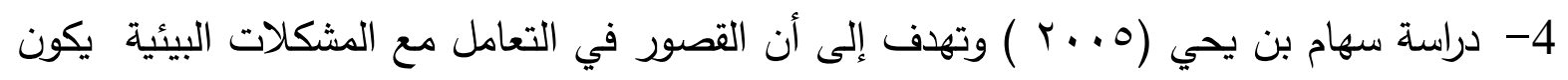

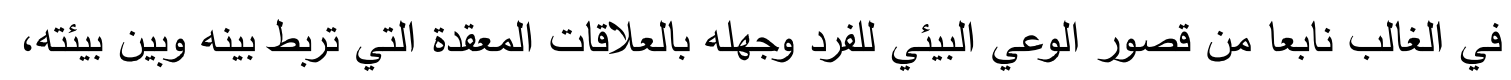

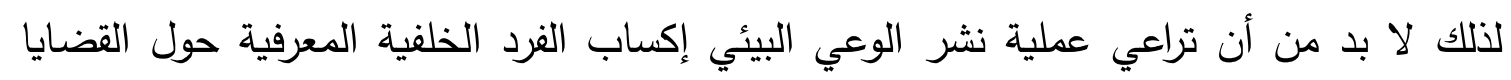

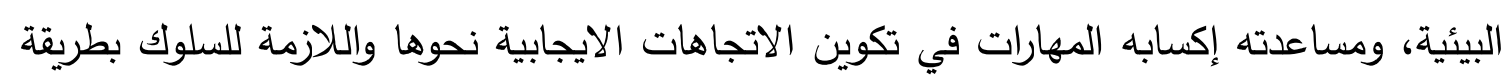

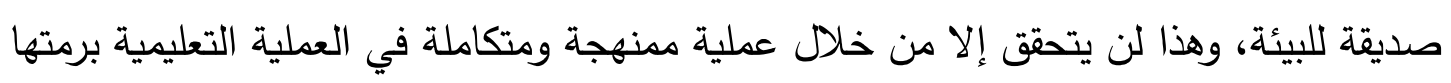

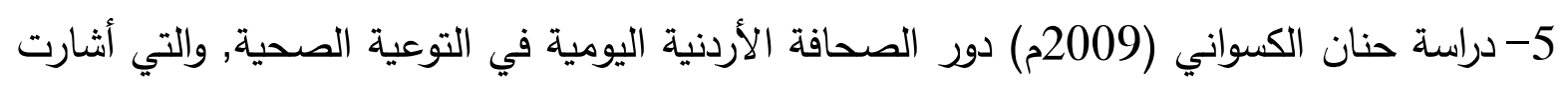
نتائجها إلي أن الأهداف التي تسعي الصحف الأردنية اليومية إلي تحقيقها من خلال نشر الإعلام

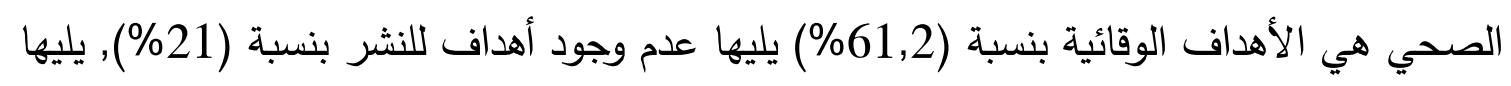
الأهداف العلاجية بنسبة (17,8\%).

6- دراسة البنا (11 • r ) هدفت إلى قياس مستوى الوعي بالجوانب المعرفية لـخاطر التلوث البيئي

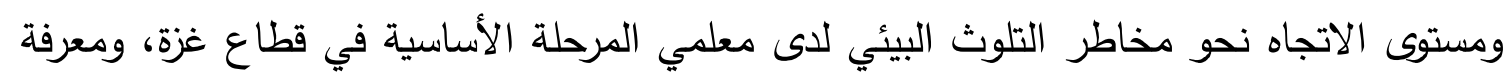

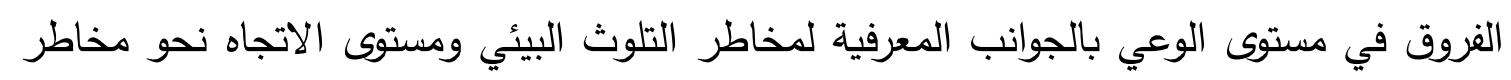

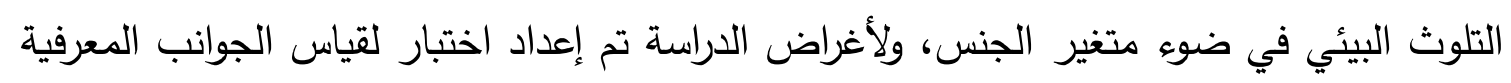


للوعي البيئي ، ومقياسا للاتجاه نحو مخاطر التلوث بمخاطر التلوث البيئي، وتم تطبيق الاختبار ومقياس الاتجاهات على عينة من معلمي المرحلة الأساسية في قطاع غزة بلغ عددهم (0. ب) معلمة، وأظهرت النتائج أن مستوى الوعي بالجوانب المعرفية لمخاطر التلوث البيئي ومستوى

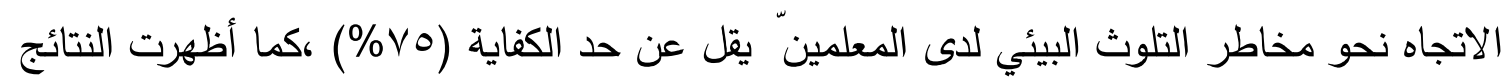
وجود فروق في مستوى الوعي بالجوانب المعرفية لمخاطر التلوث البيئي تعزى إلى جنس لصالح الإناث، وعدم وجود فروق في مستوى الاتجاه نحو مخاطر التلوث البيئي تعزى إلى جنس. ب-دراسات عن جائحة كورونا

1- دراسة خالد بن فيصل (2016) هدفت الدراسة إلى الكثف عن استخدام وسائل التواصل الاجتماعي في التوعية الصحية لمرض "كورونا" من خلال "دراسة تطبيقية" على المدن الطبية ومستشفياتها الحكومية بمدينة "الرياض" السعودية وتوصلت نتائج الدراسة إلى أنه برغم انتشار شبكات التواصل الاجتماعي في المملكة العربية السعودية، فإن (73\%) من المدن الطبية بمدينة "الرياض" ومستشفياتها الحكومية لا تمتلك منصات على شبكات التواصل الاجتماعي (يوتيوب - فيسبوك-تويتر) لاستخدامها في برامج التوعية الصحية. كما أوضحت النتائج أن (60\%) من المدن الطبية بمدينة "الرياض" لم تستخدم شبكات التواصل الاجتماعي المتاحة في التوعية حيال مرض "كورونا"، ما يعني عدم وجود استراتيجية صحية وطنية متماسكة، تسهم من خلالها كافة المدن الطبية ومستشفياتها الحكومية في الانخراط في الجهد الوطني الصحي. وأوصت الدراسة بضرورة تصميم استراتيجية توعوية صحية وطنية، منية تسهم فيها كافة مكونات المنظومة الصحية، من القطاعات الحكومية المختلفة وكذلك من قبل القطاع الصحي الخاص 2- دراسة Hussain Ibrahim (2020) مدف البحث الى معرفة ماهية الكُلفة الإجتماعية، وأهم الإنعكاسات الإجتماعية لإنتشار فيروس كورونا في المجتمعات الإنسانية، ومعرفة مدى الوعي الصحي بخطر عدوى فيروس كورونا لدى أفراد المجتمع، وتشخيص الآثار المترتبة على أفراد المجتمع نتيجة الإجراءات الوقائية الحكومية من فيروس كورونا، وقد توصل البحث الحالي لعدة نتائج ميدانية منها: إن أكثر من نصف عينة البحث وبنسبة(53\%) يُرجعون سبب إنتشار عدوى فيروس كورونا الى إنه عقوبة إلهية على الأفراد والمجتمعات. إن نسبة(61\%) من مجموع العينة يعتّدون بأن جائحة فيروس كورونا قد تمت المبالغة به إعلامياً لحد التهويل، وإن نصف عينة البحث وبنسبة(49.2\%) تكونت لديهم حالة من الرُهاب الإجتماعي لدى سماعهم بأخبار توسع جائحة المرض. إن نسبة(55.1\%) من عدد المبحوثين قد أشاروا لعدم مواجهتهم لمشكلاتٍ أُسرية 
بسبب البقاء في البيت، وإن نسبة(44.9\%) من مجموع المبحوثين قد أشاروا لتعرضهم لمشكلاتٍ أُسرية وكان أكثرها مُشكلات يتعرض لها الأبناء مع آباءهم ـ إن كل المبحوثين قد عانوا من أضرار وتكاليف مالية وإجتماعية نتيجة بقاءهم في البيوت للوقاية من فيروس كورونا سواءً من خلال القلق الق والخوف او ترك العمل والتعرض للبطالة والفقر . 3- دراسة آمال ابراهيم ومحمد كمال (2020) هدف البحث الحالي إلى التعرف على طبيعة بعض المشكلات النفسية (الوحدة النفسية ـالاكتئاب والكدر النفسي - الوساوس القهرية - الضجر اضطرابات الأكل - اضطرابات النوم - المخاوف الاجتماعية) المترتبة على جائحة فيروس كورونا المستجد Covied 19 -لدى عينة من طلاب الجامعات المصرية (الحكومية والاهلية)، وتوصلت النتائج إلى أن الضجر من أكثر المشكلات النفسية التي يعاني منها طلاب الجامعة في التوقيت الحالي، كما يعاني طالب الجامعة بدرجة متوسطة من المشكلات النفسية الاخرى، كما توصل البحث إلى وجود فروق إحصائياً في المشكلات النفية يعزى لمتغيري النوع والعمر الزمني، ولا يوجد فروق إحصائياً يعزى لمتغير البيئة.

من خلال الطرح السابق واستعراض بعض الدراسات التي اهتمت بتتمية الوعى الصحى والدراسات التى اهتمت بجائحة كورونا ، هذا ما دعى الى الاهتمام بتمية الوعى للعاملين بادارات التجميل والنظافه بالمجالس المحلية ، يمكن بلورة مجموعة من النقاط أهمها:1- تأكيد الدراسات السابقة على أن تتمية الوعى أصبح من أبرز الموضوعات التي بدأت تتاقش فى الآونه الاخيرة في المجتمع المعاصر لما تواجهه الأسر والمجتمعات من مشكلات ومعوقات وتحديات

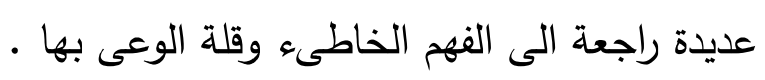

2- أوضحت الدراسات السابقة أهمية الاهتمام بتنمية الوعى للعاملين الاكثر اختلاطا بعامة المجتمع يوميا للوقاية من جائحة كورونا ـ وتتحدد مشكلة الدراسة فى التساؤل الرئيسى للاراسة وهو" ما دود الممارس العام في الخدمة الاحتماعية لتمية الوعى للعاملين للوقابة من جائحة كورونايا " ثالثاً : أهمية البحث و تتمثل في: 1. الأهمية المجتمعية:

• عدد مشكلات وقضايا الصحة في ظل الزيادة السكانية من القضايا الهامة وخصوصا قضية جائحة كورونا وما يرتبط بها من وعى صحى واجتماعى 
• أصبحت جائحة كورونا من أهم القضايا المثارة على الساحة حاليا، الأمر الذي يدعوا التخصصات المختلفة أن تبني ممارساتها على أساليب ونماذج علمية تساهم في وضع

حلول لمواجهتها.

2. 2 - الأهمية المهنية:

• المساهمة في تحقيق الاستبصار الذاتي حول إحدى القضايا الهامة التي تواجه العاملين وهى معرفة دور الممارس العام فى الخدمة الاجتماعية فى تتمية الوعى للوقاية من جائحة كورونا

• تطوير عملية الممارسة المهنية للأخصائيين بما يواكب التغيرات المجتمعية بما يساهم بقوة في دعم مكانة المهنة والاعتراف المجتمعي بدورها الفاعل لمواجهة تحديات العصر والمشكلات المجتمعية المستحدثة.

3. الأهمية التخصصية:

• الوقوف على الجهود المجتمعية الوقائية والعلاجية والإنمائية التي يقوم بها المتخصصين بإدارات التجميل والنظافة بالمجالس المحلية

• قد تثيد الدراسة الحالية في إثراء الجانب العلمي والمعرفي لمهنة الخدمة الاجتماعية. • افتقار مجال الممارسة للاهتمام بمثل هذه القضايا الهامة للعاملين فى الادارات المختلفة

للتجميل والنظافة .

رابعاً :مفاهيم البحث:

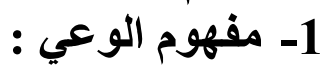

يحدد قاموس على الاجتماع " الوعي بأنه إدراك الفرد لذاته كفرد وكعضو في جماعة وإدراكه للأشياء في العالم الخارجي وكل ذلك يتم في درجات مختلفة من الوضوح والتعقيد(Julius gauld :1999,400) ويحدد معجم العلوم الإجتماعية " الوعي كلغة وكمصطلح بأنه كلغة هو الفهم وسلامة الإدراك وهو في الاصطلاح إدراك الفرد لنفسه وللبيئة المحيطة به (معجم العلوم الاجتماعية ، 132) أما المفهوم الوارد في دائرة المعارف الأمريكية يرى أن الوعي الاجتماعي هو حالة من اليقظة يدرك فيها الإنسان نفسة وعلاقاته بمن حوله من زمان ومكان وأشخاص بحيث تؤدي إلي أن تكون استجابة الفرد للمؤشرات البيئية بصور صحيحة(internationalEncyclopedia:1997,821) ويرى "نوترمان ودرورى" أن الوعي هو ذلك الجزء من الشخصية الذي يدرك به المره ما حوله ويتضمن الوعي والمشاعر والأفكار التي يفترض أنها ستكون أساسا للأنشطة التي يقوم بها الفرد وهذه الأفكار والمشاعر يمكن تبادلها مع الآخرين بل إن ذلك يمثل ضرورة هامة لبني الإنسان Graeme) :2010,24) 
وفي الجهة الأخرى نجد ماركس يعرف الوعي الاجتماعي على أنه " مجموعة الأفكار والنظريات والآراء والمشاعر الإجتماعية والعادات والتقاليد التي توجه الناس والتي تعكس واقعهم أي مجتمعهم الإنساني(سمير نعيم : 150،1996)

\section{و يقصد الباحث بمفهوم الوعي فى هذه الاراسة بأنه}

إدرالك وإلمام العاملين بالمجلس المحلية في المجتمع بالمعلومات والحقائق الصحية والبيئية وتبنّي نمط حياة وممارسات صحية سلمية, من أجل رفع المستوى الصحي والبيئى للمجتمع, والحدّ من انتشار الأمراض وتتمية إحساسهم بالمسئولية الاجتماعية تجاه صحتهم وصحة الآخرين. كما يقصد الباحث بمفهوم تنمية الوعي إجرائيا ما يلي: 1. تثقيف العاملين بالمجلس المحلية في المجتمع بالصحة العامة والتغذية السليمة والمشكلات الصحية وكيفية الوقاية والتعامل مع فيروس كورونا.

2. نشر الوعي لدي العاملين بالمجلس المحلية في المجتمع بالعادات الصحية والبيئية السيئة وحثهم وتشجعيهم إلي تغيرها إلي عادات صحية وبيئية سليمة وتكوين اتجاهات إيجابية للوقاية من خطر

$$
\text { فيروس كورونا . }
$$

3. تتمية شعور العاملين بالمجلس المحلية في المجتمع بالمسئولية الاجتماعية تجاه صحته وصحة

$$
\text { الغير تجاه فيروس كورونا. }
$$

2- الممارسة العامة للخدمة الاجتماعية

تعددت وتتوعت التعريفات التي تحاول تحديد تعريف الممارسة العامة في الخدمة الاجتماعية فالممارسة العامة منظور شامل للممارسة يركز على المستولية المتبادلة بين الأخصائي الاجتماعي (نسق مقدم الخدمة) يتضمن الأخصائي في مواقع الممارسة المختلفة كثخص مهني له العديد من الاتجاهات والموارد الأخرى المتاحة في المجتمع المحلي والتي قد تساعد العميل في الحصول عليها، أما العميل (نسق الهدف) فيتضمن العميل كشخص في حد ذاته له العديد من الاتجاهات وقد يكون "أسرة، أصدقاء، مجتمع محلي."

فهي نزع من الممارسة المهنية للخدمة الاجتماعية تعتمد على انتقاء المداخل أو النماذج المهنية من جملة النماذج والمداخل العلمية المتاحة أمام الأخصائيين الاجتماعيين واستخدامها في التخخل المهني مع نسق الهدف بما يتتاسب مع نسق العميل ونسق المشكلة ( جمال شحاته : 2009، 27) . كما تعرف بأنها منظور شامل للممارسة يمكن الأخصائي الاجتماعي كمارس عام للتعامل مع كافة أو جميع مستويات انساق عملاء الخدمة الاجتماعية بما يتناسب مع طبيعة المشكلة سواء كان ذلك "فرد، 
زوجان، اسر، جماعات، منظمات، مجتمعات محلية، مجتمعات عالمية" كما يمكن للأخصائي الاجتماعي من انتقاء النظريات والطرق المتعددة للخدمة الاجتماعية مع التركيز على مواطن القوي لدى العميل وقدراته عند التعامل مع الموقف الإشكالي بدلا من التركيز على مواطن الضعف مع حشد قوي العملاء

واستخدام الموارد البيئية في حل مشكلات نسق العملاء(ماهر ابو المعاطى : 2009، 132)

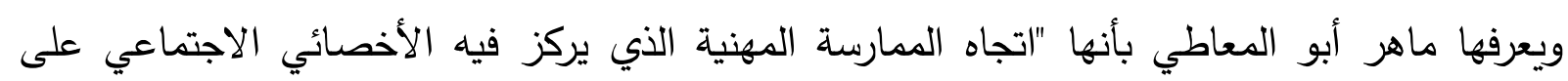
استخدام الأنساق البيئة والأساليب والطرق الفنية لحل المشكلة". دون تفضيل التركيز على تطبيق طريقة من طرق الخدمة الاجتماعية في إشباع احتياجاتهم ومواجهة مشكلاتهم واضعا في الاعتبار كافة أنساق التعامل (فرد، أسرة، جماعة صغيرة، منظمة مجتمع) مستندا على أساس معرفية ومهارة وقيمية تعكس في تعاملها التخصصات الأخرى لتحقيق الأهداف وفقا لمجال الممارسة( عبد الفتاح غزال :2008، 171). فمنظور الممارسة العامة منظور شامل يركز على المسئولية المتبادلة بين الأخصائي الاجتماعي والعميل للتعامل مع المشكلات في البيئة التي يعيش فيها ويعتبر نسق الأخصائي الاجتماعي (نسق مقدم الخدمة)، أما العميل (نسق الهدف) فيضمن العميل كشخص في حد ذاته له العدد هن اله الاتجاهات(Davids Berzotes:2000,5). وتتحدد مهام الأخصائي الاجتماعي كممارس العام على النحو التالي: 1) يمتلك العديد من المهارات التي تمكنه من تصميم وتطبيق تولفة من المعارف والقيم التي تتناسب مع طبيعة كل موقف من المواقف الإشكالية التي يتعامل معها. 2) يعتبر الممارس العام هو المسئول عن توجيه عملية المساعدة وإحداث التغيرات المطلوبة بصفته محرك عملية المساعدة. 3) يتعامل الممارس العام مع كافة الأنساق المرتبطة بالموقف الإشكالي سواء التي تحتاج للمساعدة (كنسق العميل- نسق المشكلة) أو الأنساق الأخرى (كنسق الفعل - نسق المستهدف). 4) يعمل في إطار سياسة ولوائح المنظمة التي يعمل بها، إذ أنه يعتبر مثثلا لها.

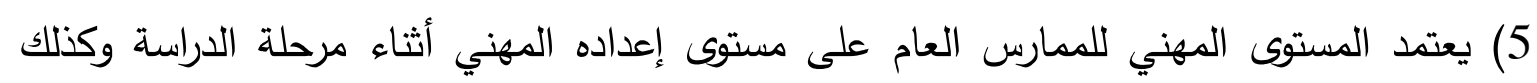
على النمو المهني المستمر بعد التخرج أثناء عمله ويسق ذلك استعداده الشخصي للعمل المهني. 6) يمارس دوره المهني بالتعاون مع فريق العمل من التخصصات التي تتطلبها عملية المساعدة ويكون مسئول عن تنسيق العمل فيما بينهح لحل المشكلة. 


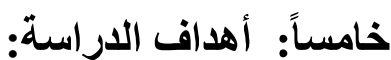 \\ تسعى الدراسة إلى تحقيق الأهداف التالية:}

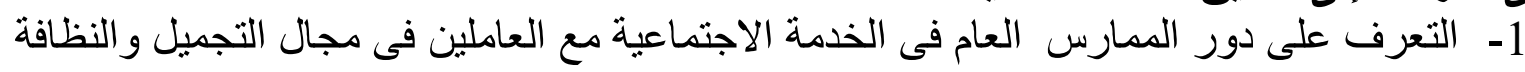

بالمجالس المحلية لتنمية وعيهم بجائحة كورونا.

2- تحديد معوقات دور الممارس العام فى الخدمة الاجتماعية مع العاملين فى مجال التجميل و النظافة بالمجالس المحلية لتنمية وعيهم بجائحة كورونا .

3- تحديد المقترحات التى تزيد من فاعلية دور الممارس العام فى الخدمة الاجتماعية مع العاملين فى مجال التجميل و النظافة بالمجالس المحلية لتنمية وعيهم بجائحة كورونا.

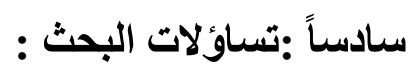

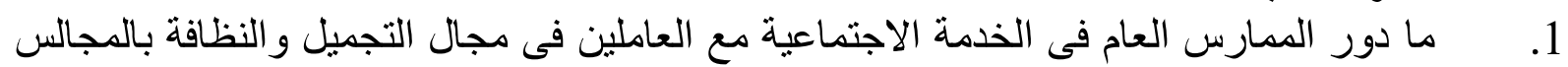

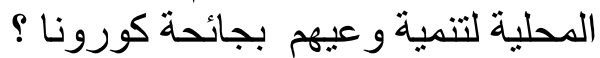

2. ما هي المعوقات التى تحد من دور الممارس العام فى الخدمة الاجتماعية مع العاملين فى مجال

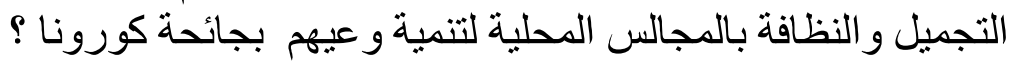

3. ما هى المقترحات التى تزيد من فاعلية دور العام فى الخدمة الاجتماعية مع العاملين فى مجال

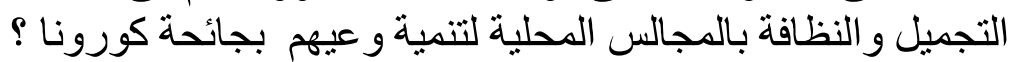

\section{سابعاً :الاستر اتيجية المنهجية للبحث: \\ 1-نوع الاراسة والمنهج:}

تعتبر هذه الدراسة من الدراسات الوصفية لما تتميز به هذه النوعية من الدراسات فى قدرتها على الوصف

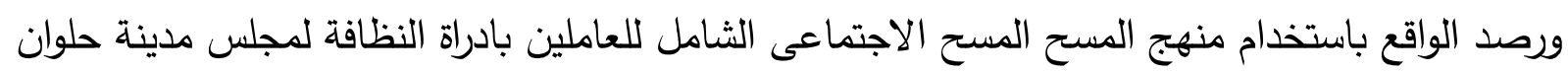

\section{2-مجالات الدراسة.}

(أ) المجال البشرى : تم تطبيق ادوات البحث على كل العامليين بالمجلس المحلى والذى بلغ

$$
\text { عددهم ( 50) عامل }
$$

(ب) المجال المكانى : تم اختيار مجلس محلى حلوان وذلك لوجود نسبة كبيره من

المصابيين بالمنطقة

(ج) المجال الزمنى : تم تطبيق ادوات البحث خلال فترة زمنية قدرها شهر من

$$
\text { 2020/7/5 }
$$




$$
\text { 3- أدوات الدراسة }
$$

أ- إستبيان للعاملين لمعرفة دور الممارس العام فى الخدمة الاجتماعية لتنمية الوعى للوقاية من

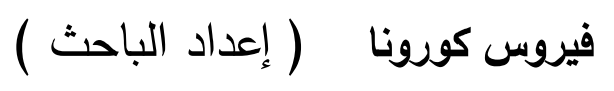

تصميم قائمة الاستبيان

لإعداد وبناء الاستمارة قام الباحث بالعديد من الخطوات أهمها ما يلي:

- الاطلاع على الإطار النظري والدراسات السابقة.

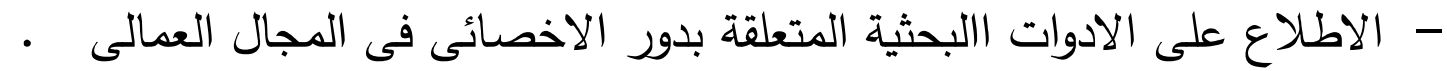
خطوات إعداد الاستمارة: تم عرض الاستمارة في صورته الأولية (35) عبارة على (7) من المتخصصين في مجالس المحلية واعضاء هيئة التدريس ؛ وذلك للحكم على صلاحية الاستمارة ومدى صلاحية كل عبارة للبعد، وتم إجراء التعديلات اللازمة خاصة فيما يتعلق هئ بحذف (5) عبارات ، وإعادة صياغة بعض عبارات، والإبقاء على العبارات التي اتفق عليها

$$
\text { وتكون الاستمارة من قسمين: المكمين ( 30) عبارة . }
$$

القسم الأول تضمن معلومات عامة عن عينة الدراسة وهي معلومات عن النوع ، السن ، المؤهل.

القسم الثاني: أثتمل هذا القسم (30) فقرة توضح اراء مفردات عينة الدراسة نحو دور

\begin{tabular}{|c|c|c|c|}
\hline$y$ & الى حد ما & نعم & درجة الموافقة \\
\hline 1 & 2 & 3 & الوزن المرجح \\
\hline
\end{tabular}

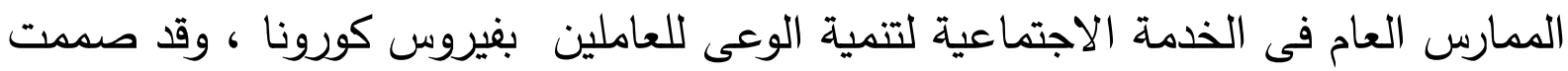
الاستمارة بطريقة " ليكرت" على مقياس ثلاثى الاتجاه، حيث كان لكل إجابة وزن مرجح وذلك كما يلى :

قياس صدق الاستبيان أ- قياس صدق المحكمين 
قام الباحث بعرض الاستبيان على مجموعة من الخبراء والمختصين في مجال الخدمة الاجتماعية لمعرفة مدى ملائمة العبارات ، ومن ثم حساب مدى اتفاق كل عبارة مع عبارات

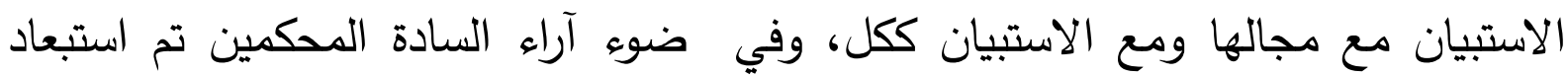
خمسة (5) عبارات لم يتم الاتفاق عليها وتعديل صياغة بعض العبارات الأخرى ليصبح عدد العدي عبارات الاستبيان (30) عبارةً

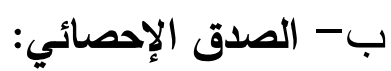
يبين جدول قيمة معاملات الصدق الإحصائي لاستمارة استبيان ، ويُعرف معامل الصدق الإحصائي بأنه

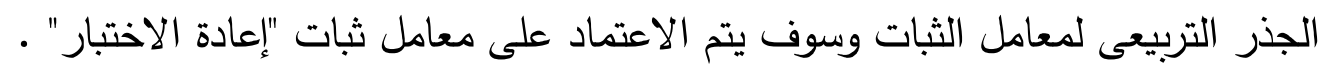
جدول ( ب ) معاملات الصدق الإحصائي لاستمارة الاستبيان

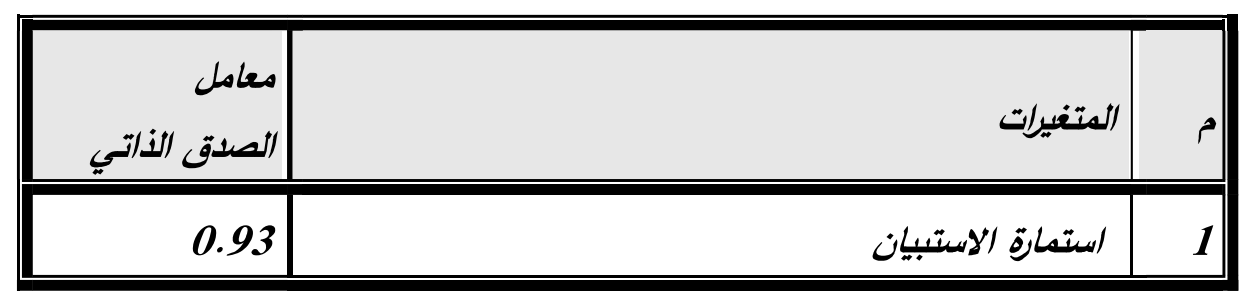

ويتضح من الجدول السابق أن قيمة معامل الصدق الإحصائي لاستمارة إستبيان للعاملين لمعرفة دور

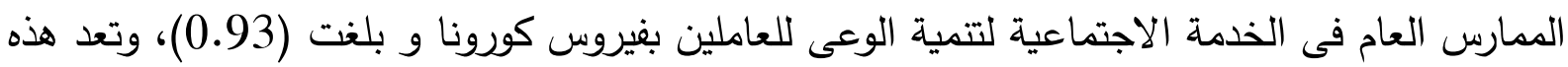
القيم مرتفعة ومقبولة وتفي بأغراض الدراسة. قياس ثبات استمارة الاستبيان

للتأكد من ثبات استبيان دور الممارس العام فى الخدمة الاجتماعية لتتمية الوعى للعاملين فى

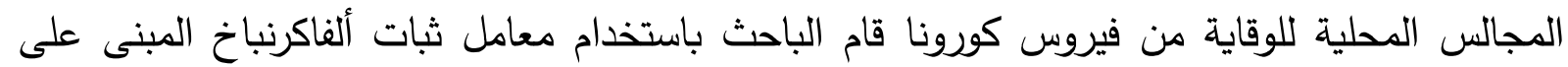

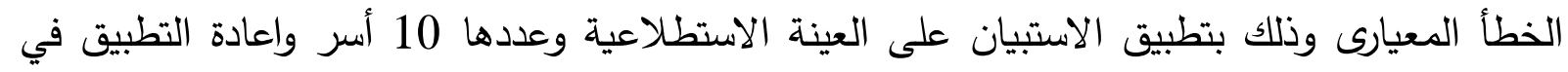
مدة لا تقل عن 15 يوماً وكانت النتائج كالتالي:- 
جدول( ج ) نتائج معامل ثبات باستخدام الفا كرونباخ بطريقة الاختبار وإعادته لاستبيان دور الممارس العام فى الخدمة الاجتماعية لتنمية الوعى للعاملين فى المجالس المحلية للوقاية من فيروس كورونا

$(10=\dot{0})$

\begin{tabular}{|c|c|c|}
\hline معامل الفا كرونباخ & عدد فقرات البعد & 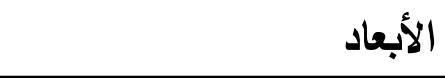 \\
\hline$* 0.734$ & 11 & دور الممارس العام \\
\hline$* * 0.968$ & 9 & معوقات الممارس العام \\
\hline$* * 0.798$ & 10 & مقترحات دور الممارس العام \\
\hline$* * 0.880$ & 30 & ع المقياس \\
\hline
\end{tabular}

يتضح من نتائج جدول السابق التأكد من ثبات استبيان دور الممارس العام فى الخدمة الاجتماعية ، حيث ان الاداة تتمتع بمعامل ثبات الفا كرونباخ عالي تراوح ما بين ( 0.734 - 0.968 ) تؤكد ثبات الاداة وتسمح باستخدامه لأغراض وتحقيق هدف البحث. ثامناً : المعالجة الاحصائية للبيانات

تم استخدام برنامج SPSS Ver.19 الاحصائي للمعالجة الإحصائية للبيانات على الحاسب الآلي ، كما

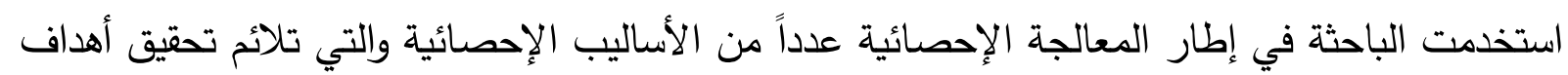
الدراسة وهى: - معامل كرونباخ لاعادة الاختبار لقياس ثبات لاستمارة الاستبيان. - الصدق الإحصائي: الجذر التربيعى لمعامل الثبات. - المتوسطات والتكرارات لقياس اتجاهات عينة البحث وتفسير ومناقشة النتائج - المتوسط المرجح: وتم حسابه للمقياس الثلاثي عن طريق:

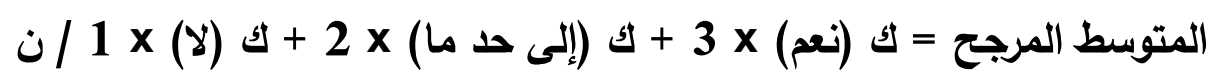
• :

يمكن الحكم على مستوى دور الممارس العام فى الخدمة الاجتماعية لتتمية الوعى للعاملين بفيروس كورونا باستخدام المتوسط المرجح حيث تكون بداية ونهاية فئات المقياس الثلاثي نعم (ثلاثة درجات)، إلى حد ما (درجتين)، لا (درجة واحدة)، تم ترميز وإدخال البيانات إلى الحاسب الآلي، ولتحديد طول 
خلايا المقياس الثلاثي (الحدود الدنيا والعليا)، تم حساب المدى = أكبر قيمة - أقل قيمة (3 - 1 = 2)، تم تقسيمه على عدد خلايا المقياس للحصول على طول الخلية المصحح (3/2= 0.67) وبعد ذلك تم إضافة هذه القيمة إلى أقل قيمة في المقياس أو بداية المقياس وهى الواحد الصحيح وذلك لتحديد الحد الأعلى لهذه الخلية, وهكذا أصبح طول الخلايا كما يلي :

\begin{tabular}{|c|c|}
\hline مستوى منخفض & إذا تراوحت قيمة المتوسط للعبارة أو البعد بين 1 - 1.67 \\
\hline مستوى متوسط & إذا تراوحت قيمة المتوسط للعبارة أو البعد بين أكثر من 1.67 - 2.35 \\
\hline مستوى مرتقع & إذا تراوحت قيمة المتوسط للعبارة أو البعد بين أكثر من 2.35 : 3 \\
\hline
\end{tabular}
تاسعاً:نتائج البحث الميدانى:

نتائج متعلقة بخصائص عينة الاراسة: $-1$

الجنس : (الجن

(l)

\begin{tabular}{|c|c|c|}
\hline$\%$ & التكرار & الجنس \\
\hline 80 & 40 & ذكر \\
\hline 20 & 10 & انثى \\
\hline$\% 100$ & 50 & المجموع \\
\hline
\end{tabular}

يتضح من الجدول السابق: أن الغالبية العظمى من الذكور حيث بلغت نسبتهم 80\% ، ونسبة الاناث بلغت 20\% ، قد يرجع ذلك الى رغبة الذكور فى العمل بإدارة التجميل والنظافة الى جانب آخر ان الذكور لديهح قدرة على العمل فى • الحرارة

(ب) السن

جدول رقم ( 2 ) يوضح متغير السن

\begin{tabular}{|c|c|c|}
\hline$\%$ & التكرار & السن \\
\hline 10 & 5 & من 25 سنه لاقل من 30سنه \\
\hline 30 & 15 & من 30سنه لاقل من 35سنه \\
\hline 60 & 30 & من 40سنه فأكثر \\
\hline$\% 100$ & 50 & المجموع \\
\hline
\end{tabular}


يتضح من الجدول السابق ان الغالبية العظمة من عينة الدراسة تقع فى الفئة العمرية من 40 سنة حيث تبلغ نسبتهم 60\%، وبذلك فى المرتبة الاولى ، بينما يأتى فى المرتبة الثانيةالعاملين الذين يقعون فى الفئة العمرية من 30سنه لاقل من 35 سنه فقد بلغت نسبتهم 30\% ، بينما جأء فى الترتيب الثالث للعاملين الذين يقعون فحى الفئة العمرية من 25 سنه لاقل من 30سنه حيث بلغت نسبتهم 10\% ـ مدا يعكس ذلك ان العاملينممن يتعرضون للاصابه بفيروس كورونا اكثر من غيرهم مما زاد من أهمية دراسة دور الممارس فى تتمية الوعى للعاملين بفيروس كورونا . المؤهل الدراسي

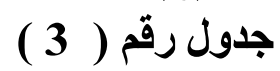

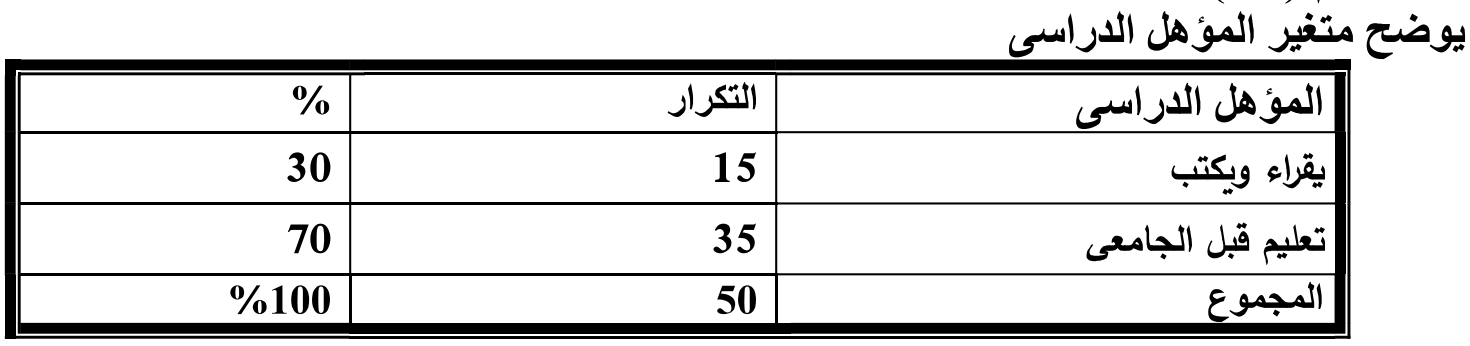

يتضح من الجدول السابق :

ان الغالبية العظمة من العاملين فى إدارة التجميل والنظافة بمجلس مدينة حلوان حاصلين على تعليم قبل الجامعة فقد بلغت نسبتهم 70\%وهى بذلك تاتى فى المرتبة الاولى ، قد يرجع ذلك الى ان أهم طموحات الأسر الفتيرة فى ذلك الوقت هو الحصول على اى مستوى تعليمى قبل الجامعى ، بينما يأتى فى المرتبة الثانية العاملين الذين يقرأون ويكتبون فقد بلغت نسبتهم 30\% وقد يرجع ذلك الى عدم اهتمامهم بالتعليم فى الصغر أو عدم قدرة الأسر على تعليم ابنائها فى تلك الفترة . 


\section{نتائج متعلقة بتساؤلات الاراسة :}

السؤال الاول : ما دور الممارس العام فى الخدمة الاجتماعية مع العاملين فى مجال التجميل والنظافة

بالمجالس المحلية لتتمية وعيهم بجائحة كورونا ؟

جدول ( 4 ) يوضح دور الممارس العام فى تنمية وعى العمال بجائحة كورونا

\begin{tabular}{|c|c|c|c|c|c|c|c|c|c|c|c|}
\hline \multirow{2}{*}{ الترتيب } & \multirow{2}{*}{ المعياري } & \multirow{2}{*}{ المرجح } & \multirow{2}{*}{ الاوزان } & \multicolumn{2}{|c|}{ غير موافق } & \multicolumn{2}{|c|}{ إلى حد ما } & \multicolumn{2}{|c|}{ موافق } & \multirow[b]{2}{*}{ العبارات } & \\
\hline & & & & $\%$ & ك & $\%$ & ك & $\%$ & s) & & \\
\hline 8 & 0.7 & 2.58 & 129 & $\% 12$ & 6 & $\% 18$ & 9 & $\% 70$ & 35 & 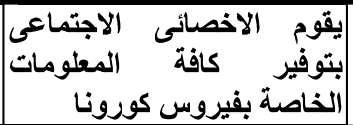 & 1 \\
\hline 4 & 0.53 & 2.72 & 136 & $\% 4$ & 2 & $\% 20$ & 10 & $\% 76$ & 38 & 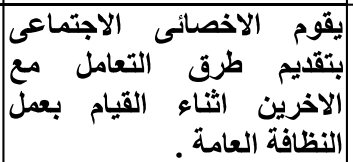 & 2 \\
\hline 7 & 0.64 & 2.7 & 135 & $\% 10$ & 5 & $\% 10$ & 5 & $\% 80$ & 40 & | للتعامليه مع الاسرهات والمحافظة & 3 \\
\hline 6 & 0.61 & 2.7 & 135 & $\% 8$ & 4 & $\% 14$ & 7 & $\% 78$ & 39 & |كلو منا على حذه اجتماعات فردية] & 4 \\
\hline 11 & 0.8 & 2.4 & 120 & $\% 20$ & 10 & $\% 20$ & 10 & $\% 60$ & 30 & 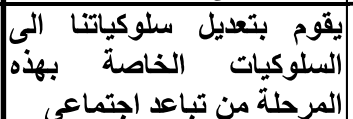 & 5 \\
\hline 2 & 0.6 & 2.8 & 140 & $\% 10$ & 5 & - & - & $\% 90$ & 45 & |الخاصة بطيعة وضعل القرارات & 6 \\
\hline 3 & 0.63 & 2.74 & 137 & $\% 10$ & 5 & $\% 6$ & 3 & $\% 84$ & 42 & |ميقاجهة كورونات & 7 \\
\hline 1 & 0.47 & 2.88 & 144 & $\% 6$ & 3 & - & - & $\% 94$ & 47 & 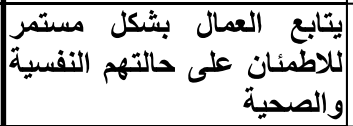 & 8 \\
\hline 5 & 0.46 & 2.7 & 135 & - & - & $\begin{array}{r}12.5 \\
\%\end{array}$ & 15 & $\begin{array}{r}87.5 \\
\%\end{array}$ & 35 & |للازومة لاجراءوات الوقاية المتلزمات & 9 \\
\hline 9 & 0.7 & 2.52 & 126 & $\% 12$ & 6 & $\% 24$ & 12 & $\% 64$ & 32 & |والسوتشفيات بالتنيق بين الوحدات| & 10 \\
\hline & & & & & & & & & & |كورونامات الطبية & \\
\hline 10 & 0.78 & 2.46 & 123 & $\% 18$ & 9 & $\% 18$ & 9 & $\% 64$ & 32 & [يقدم لنا اساليب جمع القمامة] & 11 \\
\hline \multirow{2}{*}{ مرتفع م مرت } & \multirow{2}{*}{0.65} & 2.65 & \multicolumn{9}{|c|}{ المتغير ككل } \\
\hline & & 88.33 & & & & & & & & يـة & النسب, \\
\hline
\end{tabular}




\section{يوضح البدول السابق أن:}

ان مستوى دور الممارس العام فى الخدمة الاجتماعية لتتمية وعى العاملين بادارة التجميل والنظافة

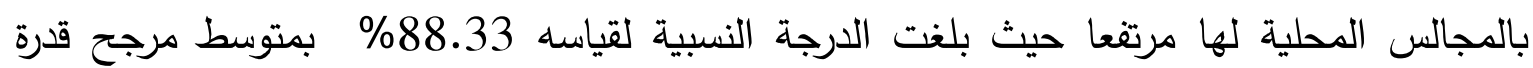

وقد جاءت أكثر الاستجابات لدور الممارس العام فى الخدمة الاجتماعية لتتمية وعى العاملين بادارة التجميل والنظافة بالمجالس المحلية مرتبة حسب الاستجات لوري المارسياتها كما يلى: - - - يتابع العمال بشكل مستمر للاطمئان على حالتهم النفسية والصحية

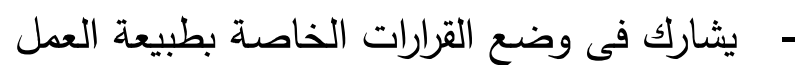
- - مقدم اللوحات الارشادية لمواجهة كورونا

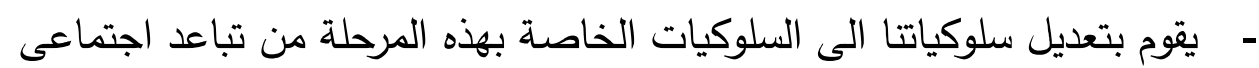
- - مقوم بتوفير الستلزمات اللازمة لاجراءات الوقاية - - ميقوم بعمل اجتماعات فردية لكل منا على حده

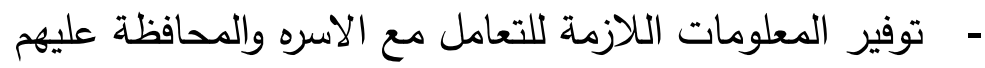

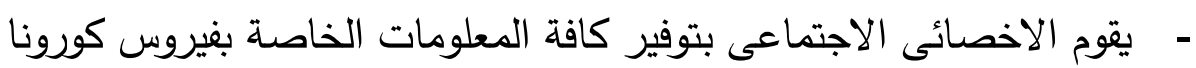

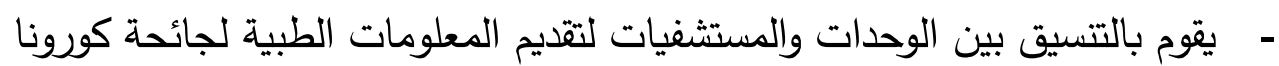

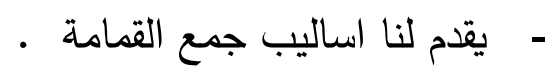

- - يقوم الاخصائى الاجتماعى بتقديم طرق التعامل مع الاخرين اثناء القيام بعمل النظافة العامة . وهذا قد يرجع ذلك الى ان الاعداد المهنى الخاص بأدارة الازمات والدورات التدريبية التى تقدم لهم فى

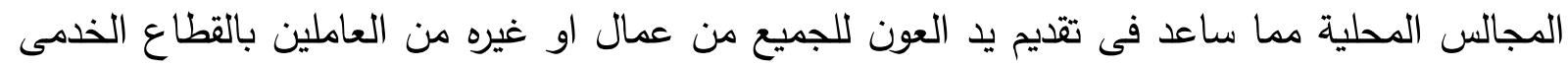
الذى يعمل يوميا للدحافظة على نظافة المجتمع واليد المساعدة لوزارة الصحة فى مواجهة خطر جائحة

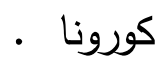

نستخلص مما سبق أن دور الممارس العام فى الخدمة الاجتماعية لتتمية وعى العاملين بادارة التجميل والنظافة بالمجالس المحلية وجاء بنسبة 91\% وهى نسبة مرتفعة . ( ب ) السؤال الثانى : المعوقات التى تحد من دور الممارس العام فى الخدمة الاجتماعية مع العاملين

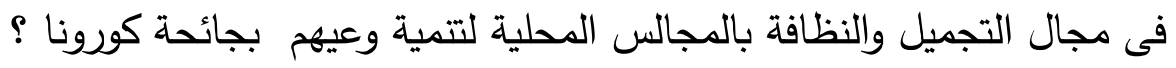


جدول ( 5 ) يوضح معوقات دور الممارس العام مع العمال لتنمية وعيهم بجائحة كورونا ( 50 (ن)

\begin{tabular}{|c|c|c|c|c|c|c|c|c|c|c|c|}
\hline \multirow{2}{*}{ الترتيب } & \multirow{2}{*}{ الانحرف } & \multirow{2}{*}{ مزنح } & \multirow{2}{*}{ مجموع } & \multicolumn{2}{|c|}{ غير موافق } & \multicolumn{2}{|c|}{ إلى حد ما } & \multicolumn{2}{|c|}{ موافق } & \multirow[b]{2}{*}{ العبارات } & \multirow{2}{*}{ م } \\
\hline & & & & $\%$ & ك & $\%$ & 5 & $\%$ & 5) & & \\
\hline 7 & 0.61 & 2.54 & 127 & $\% 6$ & 3 & $\% 34$ & 17 & $\% 60$ & 30 & ضين العاملين الوعى الاجتماعى & 1 \\
\hline 8 & 0.72 & 2.42 & 121 & $\% 14$ & 7 & $\% 30$ & 15 & $\% 56$ & 28 & لمواجهة كورونار بين العاملين & 2 \\
\hline 6 & 0.71 & 2.64 & 132 & $\% 14$ & 7 & $\% 8$ & 4 & $\% 78$ & 39 & العاملين بالمجالس الوعى الصحى لاى & 3 \\
\hline 4 & 0.75 & 2.58 & 129 & $\% 16$ & 8 & $\% 10$ & 5 & $\% 74$ & 37 & بعضة التعاون بين العاملين & 4 \\
\hline 3 & 0.73 & 2.68 & 134 & $\% 16$ & 8 & - & - & $\% 84$ & 42 & كورونتا & 5 \\
\hline 9 & 0.84 & 2.34 & 117 & $\% 24$ & 12 & $\% 18$ & 9 & $\% 58$ & 29 & 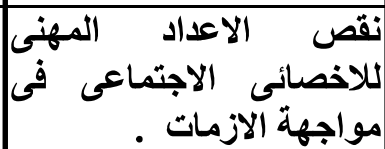 & 6 \\
\hline 5 & 0.69 & 2.64 & 132 & $\% 12$ & 6 & $\% 12$ & 6 & $\% 76$ & 38 & الاجتة الاهتماعى بلور الاخصل المجالسى & 7 \\
\hline 1 & 0.3 & 2.9 & 145 & - & - & $\% 10$ & 5 & $\% 90$ & 45 & بالمجالس المحلية المسطتبلية & 8 \\
\hline 2 & 0.63 & 2.72 & 136 & $\% 10$ & 5 & $\% 8$ & 4 & $\% 82$ & 41 & والمستلزمات & 9 \\
\hline \multirow{2}{*}{ مرتفع مستوى } & \multirow{2}{*}{0.28} & 2.60 & \multicolumn{9}{|c|}{ المتغير ككل } \\
\hline & & $\% 87$ & & & & & & & & يرية & \\
\hline
\end{tabular}

\section{يوضتح الجدول السايق أن:}

• ان مستوى معوقات دور الممارس العام فى الخدمة الاجتماعية لتتمية وعى العاملين بادارة التجميل والنظافة بالمجالس المحلية لها مرتفعا حيث بلغت الدرجة النسبية لقياسه 85\% بمتوسط مرجح قدرة

وقد جاءت أكثر الاستجابات ان مستوى معوقات دور الممارس العام فى الخدمة الاجتماعية لتتمية وعى العاملين بادارة التجميل والنظافة بالمجالس المحلية لها مرتبة حسب اولوياتها كما يلى: • ضعف الخطط المستقبلية بالمجالس المحلية • •قص الامكانيات والمستلزمات الخاصة بكورونا ل 
• ضعف التسيق بين الادارات المختلفة فى مواجهة كورونا قلة التعاون بين العاملين بعضهم ببعض •

" قلة الاهتمام بدور الاخصائى الاجتماعى داخل المجالس المحلية • ضعف الوعى الصحى لدى العاملين بالمجالس المحلية • ضعف الوعى الاجتماعى بين العاملين

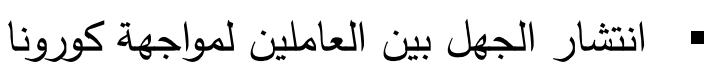

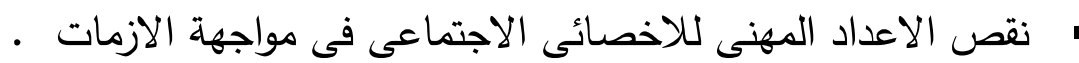
وهذا قد يرجع الى طبيعة العمل واسلوب القيادة داخل الادارات والمجالس بصفه عامة ومدى تحكم رؤساء المجالس فى طبيعة عمل الموظفين بكل القطاعات والادارات . او قد يرجع الى عدم امتلاك تلك المجالس للامكانيات التى تساعدها على اداء العاملين بوظائفها بصورة

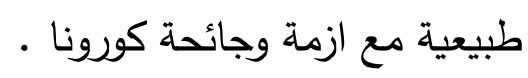
نستخلص مما سبق أن مستوى معوقات دور الممارس العام فى الخدمة الاجتماعية لتنمية وعى العاملين بادارة التجميل والنظافة بالمجالس المحلية وجاء بنسبة 82\% وهى نسبة مرتفعة . ( ج ) السؤال الثالث : المقترحات التى تزيد من فاعلية دور العام فى الخدمة الاجتماعية مع العاملين فى

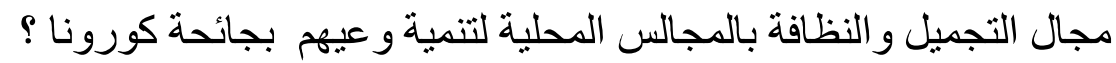
جدول ( 6 ) يوضح مقترحات تزيد من فاعلية دور الممارس العام مع العمال لتنمية وعيهم بجائحة كورونا

\begin{tabular}{|c|c|c|c|c|c|c|c|c|c|c|c|}
\hline \multirow{2}{*}{ الترتيب } & \multirow{2}{*}{ الانحراف } & \multirow{2}{*}{ مزن } & \multirow{2}{*}{ مجموع الاوزان } & \multicolumn{2}{|c|}{ غير موافق } & \multicolumn{2}{|c|}{ إلى حد ما } & \multicolumn{2}{|c|}{ موافق } & \multirow{2}{*}{ العبارات } & \multirow[b]{2}{*}{ 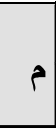 } \\
\hline & & & & $\%$ & S & $\%$ & ك & $\%$ & 5 & & \\
\hline 4 & 0.70 & 2.56 & 128 & $\% 12$ & 6 & $\% 20$ & 10 & $\% 68$ & 34 & 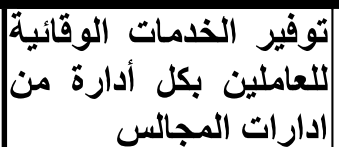 & 1 \\
\hline 9 & 0.84 & 2.36 & 118 & $\% 24$ & 12 & $\% 16$ & 8 & $\% 60$ & 30 & |الاهنية: & 2 \\
\hline 7 & 0.75 & 2.38 & 119 & $\% 16$ & 8 & $\% 30$ & 15 & $\% 45$ & 27 & |خلال اليوم من القوة العاملة & 3 \\
\hline 10 & 0.84 & 2.24 & 112 & $\% 26$ & 13 & $\% 24$ & 12 & $\% 50$ & 25 & |لوضع لوحنية كورونات توضيحية & 4 \\
\hline 3 & 0.64 & 2.56 & 128 & $\% 8$ & 4 & $\% 28$ & 14 & $\% 64$ & 32 & 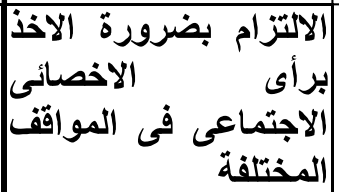 & 5 \\
\hline
\end{tabular}




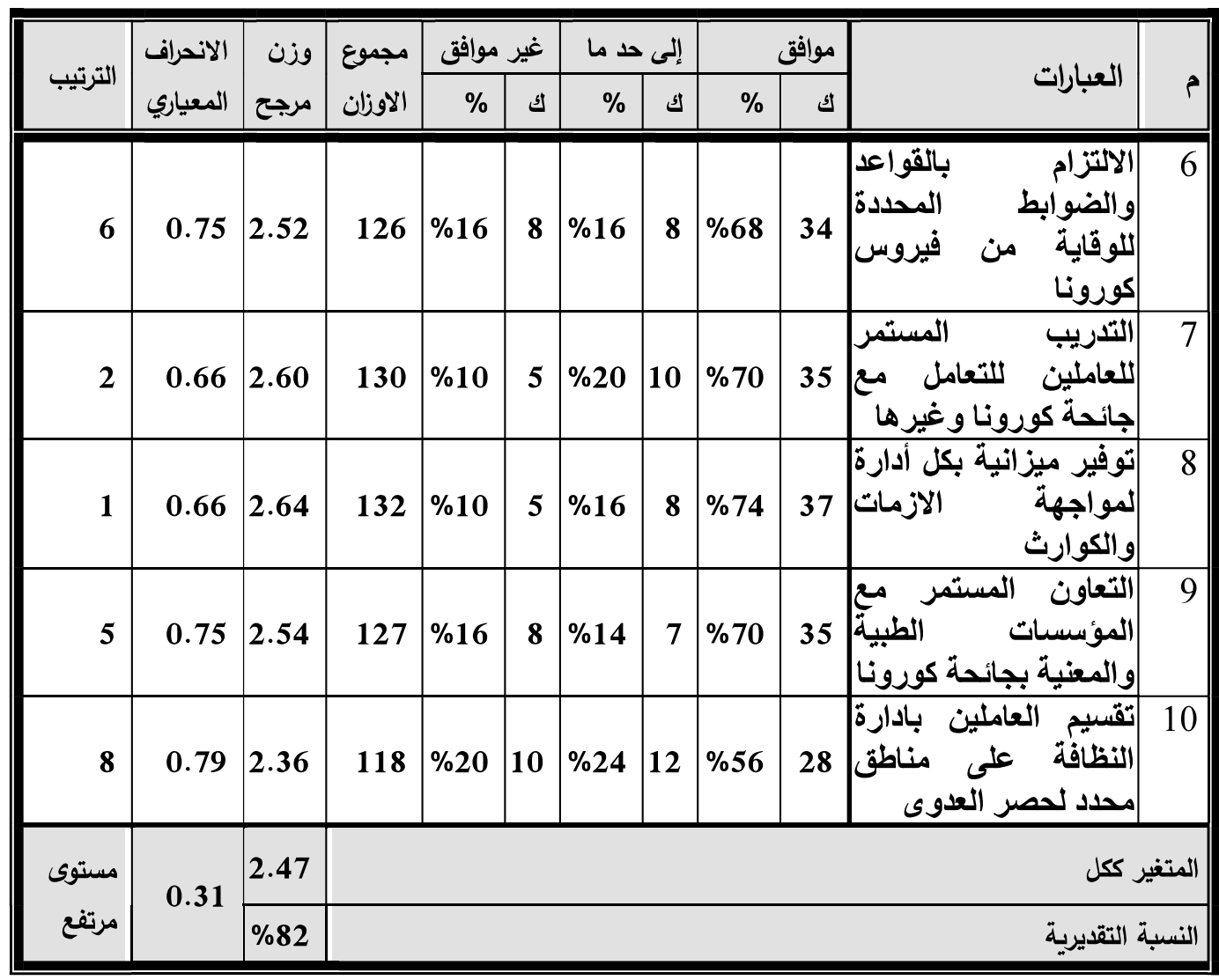

\section{يوضتح الحدول السابق أن:}

ان مستوى المقترحات التى تزيد من فاعلية دور العام فى الخدمة الاجتماعية مع العاملين فى مجال التجميل والنظافة بالمجالس الدحلية لتتمية وعيهم بجائحة كورونا لها مرتفعا حيث بلغت الدرجة النسبية لقياسه 82\% بمتوسط مرجح قدرة 2.46. وقد جاءت أكثر الاستجابات المقترحات التى تزيد من فاعلية دور العام فى الخدمة الاجتماعية مع العاملين فى مجال التجميل والنظافة بالمجالس المحلية لتمية وعيهم بجائحة كورونا مرتبة حسب لربـ اولوياتها كما يلى: توفير ميزانية بكل أدارة لمواجهة الازمات والكوارث التدريب المستمر للعاملين للتعامل مع جائحة كورونا وغيرها الالتزام بضرورة الاخذ برأى الاخصائى الاجتماعى فى المواقف المختلفة توفير الخدمات الوقائية للعاملين بكل أدارة من ادارات المجالس التعاون المستمر مع المؤسسات الطبية والمعنية بجائحة كورونا الالتزام بالقواعد والضوابط المحددة للوقاية من فيروس كورونا التقليل من القوة العاملة خلال اليوم تقسيم العاملين بادارة النظافة على مناطق محدد لحصر العدوى 


$$
\begin{aligned}
& \text { تشجيع المؤسسات الاهلية فى حملات الوقاية } \\
& \text { لوحات توضيحية للوقاية من كورونا }
\end{aligned}
$$

- وقد يرجع الى اهمية دور الممارس العام فى الخدمة الاجتماعية فى المجالس المحلية او قد يرجع الى وعى العاملين بمدى أهمية دور الممارس العام معهم فى العمل وما له من أهمية فى مواجهة كورونا من خلال الاجراءات والمهام التى كان يقوم بها خلال فترة كورونا

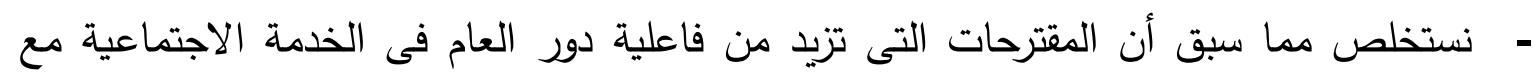
العاملين فى مجال التجميل والنظافة بالمجالس المحلية لتنمية وعيهم بجائحة كورونا وجاء

$$
\text { بنسبة 89\% وهى نسبة مرتفعة . }
$$

عاشرا : نتائج العامة للبحث : توصلت الدر اسة الى مجموعة من النقامة النتائج وهى

ان الممارس العام فى الخدمة الاجتماعية يقوم بدوره مع العاملين لتتمية وعيهم

$$
\text { بمستوى مرتفع ومن اولويات دوره هى :- }
$$

يتابع العمال بشكل مستمر للاطمئان على حالتهم النفسية والصحية

$$
\text { يشارك فى وضع القرارات الخاصة بطبيعة العمل }
$$

$$
\text { يقدم اللوحات الارشادية لمواجهة كورونا }
$$

يقوم بتعديل سلوكياتتا الى السلوكيات الخاصة بهذه المرحلة من تباعد

$$
\text { اجتماعى }
$$

$$
\text { يقوم بتوفير المستلزمات اللازمة لاجراءات الوقاية }
$$

مجموعة من المعوقات التى تواجه الممارس العام فى الخدمة الاجتماعية

$$
\text { ومنها :- }
$$

ضعف الخطط المستقبلية بالمجالس المحلية

نقص الامكانيات والمستلزمات الخاصة بكورونا .

ضعف التسيق بين الادارات المختلفة فى مواجهة كورونا

قلة التعاون بين العاملين بعضهم ببعض .

قلة الاهتمام بدور الاخصائى الاجتماعى داخل المجالس المحلية

ضعف الوعى الصحى لدى العاملين بالمجالس المحلية

مجموعه من المقترحات التى ان تزيد من مستوى اداء الممارس العام فى تتمية

الوعى للعاملين لمواجهة جائحة كورونا ومنها :-- 


$$
\text { توفير ميزانية بكل أدارة لمواجهة الازمات والكوارث }
$$

التدريب المستمر للعاملين للتعامل مع جائحة كورونا وغيرها

الالتزام بضرورة الاخذ برأى الاخصائى الاجتماعى فى المواقف المختلفة هائه

توفير الخدمات الوقائية للعاملين بكل أدارة من ادارات المجالس

التعاون المستمر مع المؤسسات الطبية والمعنية بجائحة كورونا

الالتزام بالقواعد والضوابط المحددة للوقاية من فيروس كورونا

$$
\text { الحادى عشر: توصيات البحث : }
$$

من خلال ما ورد فى محتوى البحث ، بالامكان وضع عدد من التصورات للارتقاء بكفاءة نظام العمل

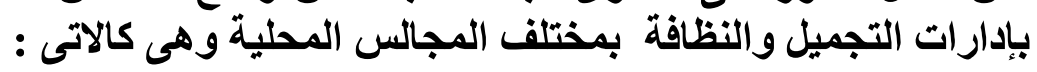

ضرورة اهتمام وزارة التضامن الاجتماعى ووزارة التمية المحلية بالاهتمام

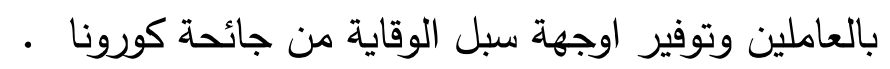

تأهيل وتدريب كل العاملين بإدارات التجميل والنظافة لكيفية مواجهة جائحة

كورونا او الأمراض المعدية والجائحات بمختلف مسمايتها.

توصى الدراسة بوضع اللافتات والاعلانات المصوره للاجراءات والتعليمات

الموصى بها للوقاية من جائحة كورونا ل 
1) أبو الحسن عبد الموجود إبراهيم(2010): الخدمة الاجتماعية (المخل المعايير-الممارسة العامة)، قنا، مذكرات غير منشورة.

2) أحمد حمدي يوسف (1983): إعداد برنامج في التربية البيئية لطلاب كليات التربية، رسالة

$$
\text { دكتوراه غير منشوره، كلية التربية، جامعة عين شمس. }
$$

3) أحمد ريان. (1425هـ):دور وسائل الإعلام في التثقيف الصحي للمرأة السعودية بمدينة الرياض، كائ،

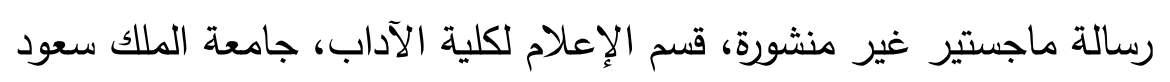

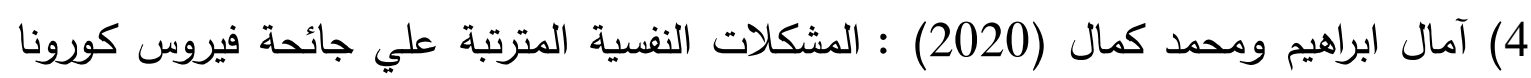

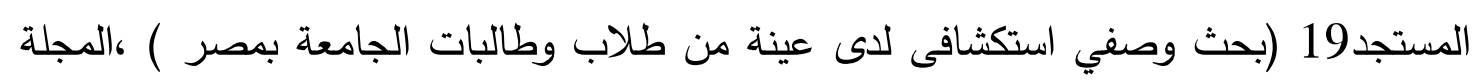

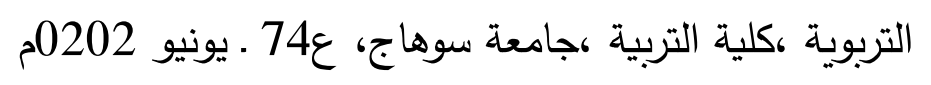

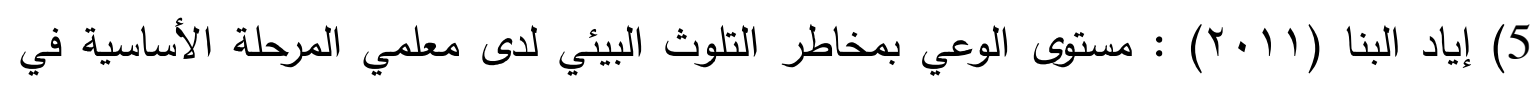

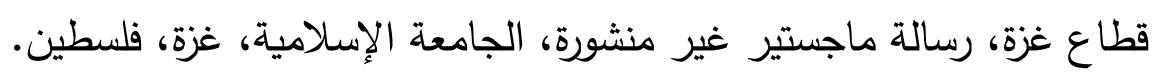

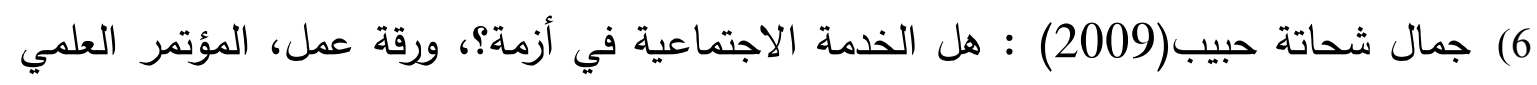
السابع، القاهرة، المعهد العالي للخدمة الاجتماعية، المجلد الأول.

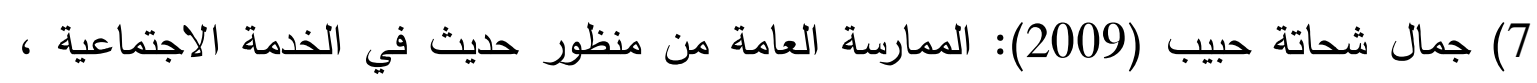
الإسكندرية، المكتب الجامعي الحديث.

8) حنان حسن صالح الكسواني (2009م):دور الصحافة الأردنية اليومية في التوعية الصحية دراسة الصادية

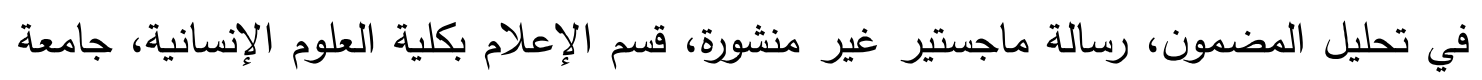
الثرق الوسط للدراسات.

9) خالد بن فيصل (2016) : استخدام وسائل التواصل الاجتماعى فى التوعية الصحية لمرض الترات

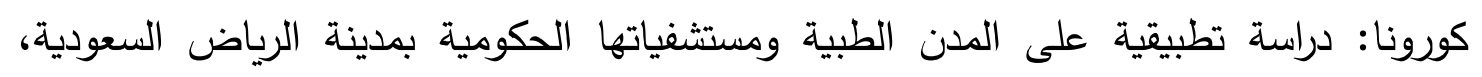

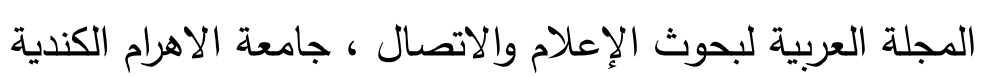

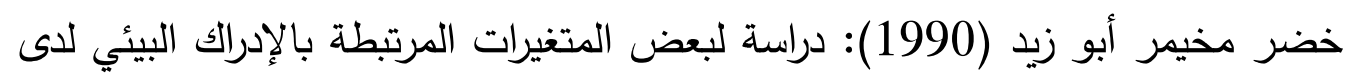

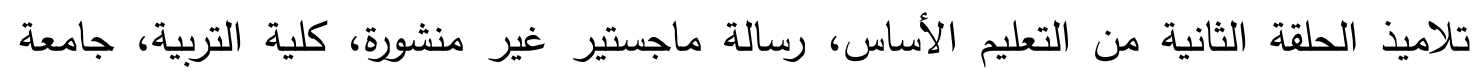

$$
\text { أسيوط. تلامن. }
$$

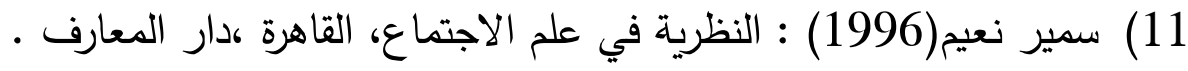

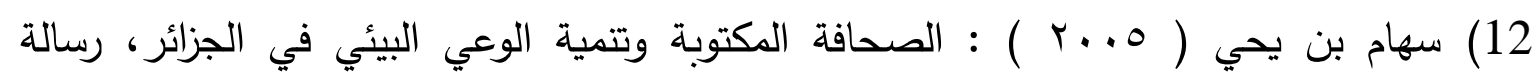
ماجستير غير منشورة. جامعة منتوري، قسنطينة، الجزائر . 
13) عبد الفتاح غزال(2008) : أبحاث حديثة في علم نفس الطفل، القاهرة، دار ماهي للنشر والتوزيع

14) عبدالله طابية وابراهيم رواشدة (2000م): مستوي الوعي الصحي لدي طالبات كليات المجتمع

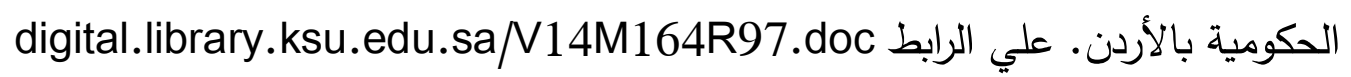
15) على إبراهيم محرم (1996): تأثير برنامج بيئي مقترح على تتمية السلوك البيئي لأعضاء الجماعة بمركز الشباب، بحث منشور، المؤتمر العلمي التاسع، كلية الخدمة الاجتماعية، جامعة حلوان. 16) علي بن حسن بن حسين (1424هـ):مستوي الوعي الصحي لاي تلاميذ الصف الثاني الثانوي طبيعي وعلاقته باتجاهاتهم الصحية في المدينة المنورة، رسالة ماجستير غير منشورة، قسم المنهج وطرق التدريس بكلية التربية، جامعة أم القري.

17) ماهر أبو المعاطي على(2009) : نماذج ومهارات التذخل المهني في الخدمة الاجتماعية، القاهرة، نور الإيمان للطباعة. 18) محمد الجوهري، عبد الحميد عبد المحسن(1991): العمل الفريقي في ممارسة الخدمة الاجتماعية، المؤتمر العلمي الرابع، جامعة القاهرة، كلية الخدمة الاجتماعية 19) محمد أمين عامرو مصطفى محمود سليمان (2009): تلوث البيئة مشكلة العصر : دراسة علمية حول مشكلة التلوث وحماية صحة البيئة، القاهرة ، دار الكتاب الحديث. 20) معجم العلوم الاجتماعية. إعداد نخبة من الأساتذة المصريين مراجعة إبراهيم مدكور، القاهرة ، الهيئة المصرية للكتاب، ب.ت. 21) نبيل أحمد حلمي (2002): الحماية القانونية الدولية للبيئة، القاهرة ،دار النهضة العربية للطبع والنشر والتوزيع.

22) Bronfen Brenner Urie (2014): The Ecology of human development Harvard University Press, USA, P. 34.

23) Davids Berzotes(2000): Advanced Generalist Social Work Practice ,London, SagePopulation .

24) Graeme A. Hodge(2010) ;social consciousness. West view.press. Boulder.Colorado.V.s.A 
25) Hussain Ibrahim Humadi: The Social Cost of the Corona Virus Pandemic Crisis: A Field Study in the Ferry District (Diyala Governorate) ,Journal of Education College Wasit University 2(39):395-432

26) international Encyclopedia(1997); Social sciences vol.9 the Macmillan Company the free press.

27) Julius gauld William kolb(1999) "a dictionary of the social sciences" tavistock publications compiled under the auspices unesco.

28) Mary Ellen Snodgrass (2013): Environmental Awareness, Finney Company, USA.

29) Northern Klein (1994): National Survey of Environmental Knowledge and Awareness, National Center for Education research and Development, Publication Series, No (20). 
دور الممارس العام فى الخدمة الاجتماعية لتنمية الوعى للعاملين للوقاية من فيروس كورونا

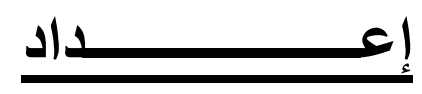

محمد عبد الحمبل مرسي محمد

استاذ مساعد بقسم مجالات الخدمة الاجتماعية بالمعهد العالى للخدمة الاجتماعية القاهرة الخداعة 
البيانات الاولية :

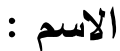

السن :

2- من 35 لاقل من 40سنه ( )

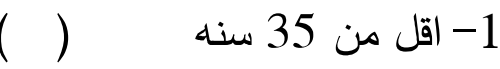

3- من 40 فأكثر

مستوى التعليم :

2 - تعليم قبل الجامعى ( )

1 ( ) بقرأ ويكتب

س 1: ما هو دور الممارس العام فى الخدمة الاجتماعية فى تنمية وعى العمال للوقاية من جائحة كورونا ج

\begin{tabular}{|c|c|c|c|c|}
\hline ע & الى حد ما & نعم & العباره & م \\
\hline & & & 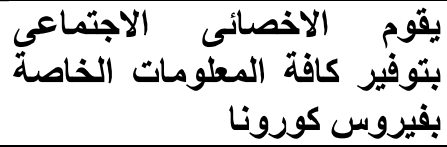 & 1 \\
\hline & & & 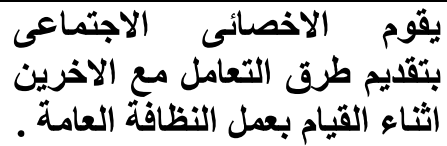 & 2 \\
\hline & & & توع الاسره المعلومات الللازمة للتعاملة عليهم & 3 \\
\hline & & & ينا على حعلى اجتماعات فردية لكل & 4 \\
\hline & & & 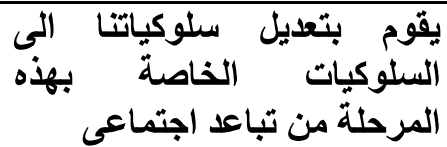 & 5 \\
\hline & & & الخاصة بطبيعة العمل القرارات & 6 \\
\hline & & & ليقواجهة كورونات & 7 \\
\hline & & & 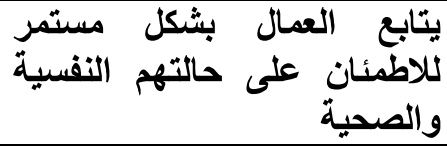 & 8 \\
\hline & & & لاجراء بتو الثوقاية المستزمات اللازمة & 9 \\
\hline & & & والطبية لجثائحة كوريات لتقيمين المعلومات & 10 \\
\hline
\end{tabular}




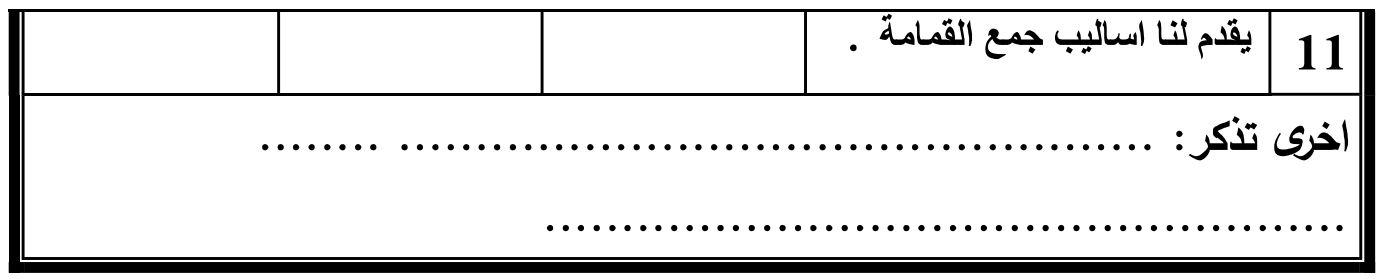

س2: ما معوقات دور الممارس العام فى الخدمة الاجتماعية فى تنمية وعى العمال للوقاية من جائحة كورونا ؟

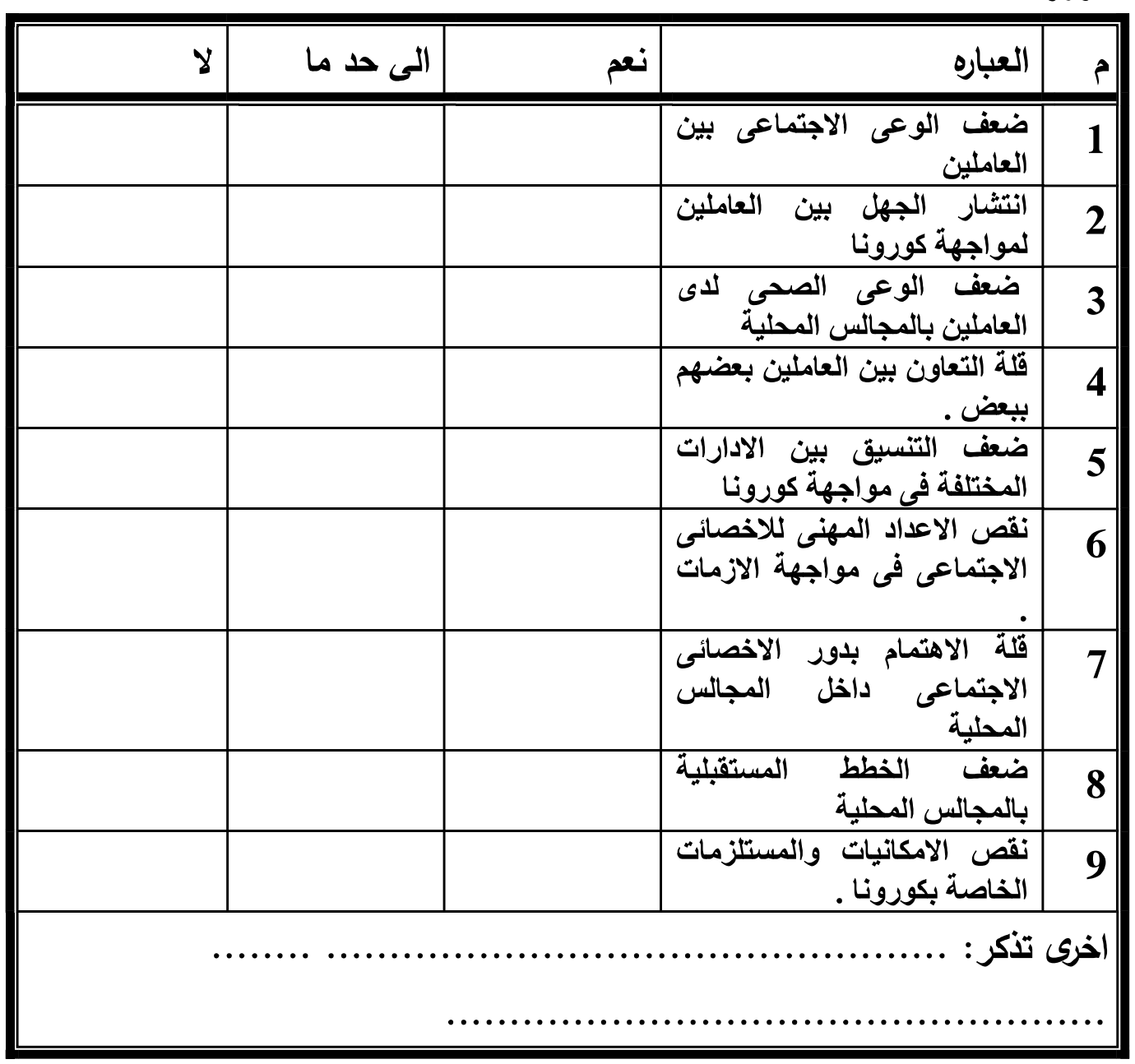


س 3: ما هى مقترحات تفعيل دور الممارس العام فى الخدة الاجتماعية مع العمال لتنمية وعيهم للوقاية من جائحة كورونا ؟ لن

\begin{tabular}{|c|c|c|c|c|}
\hline$y$ & اللى حد ما & |نعم & العباره & م \\
\hline & & & بكل أدارة من ادارات الخدائة للعاملين & 1 \\
\hline & & & تثلات الوقاية المؤسسات الاهلية فى & 2 \\
\hline & & & التيوم من القيل من العاملة خلال & 3 \\
\hline & & & من كورونا لوحات توضيحية للوقاية & 4 \\
\hline & & & 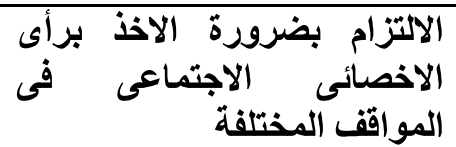 & 5 \\
\hline & & & الالتزام & 6 \\
\hline & & & 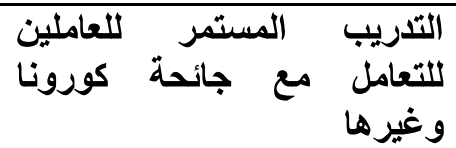 & 7 \\
\hline & & & لمواجيز ميزة الازماتية و الكوارث أدارة & 8 \\
\hline & & & الطبية والمعنية بجائحة كورونات المؤستات & 9 \\
\hline & & & تقلىيم العاملين بادارة النظافة & 10 \\
\hline
\end{tabular}


